\title{
BMPRII deficiency impairs apoptosis via the BMPRII-ALK1-BcIX-mediated pathway in pulmonary arterial hypertension (PAH)
}

H.M. Chowdhury ${ }^{1}$, N. Sharmin ${ }^{2,3}$, M. Yuzbasioglu Baran ${ }^{2,4}$, L. Long ${ }^{5}$, N. W. Morrell ${ }^{5}$, R.C. Trembath ${ }^{1,6}$, Md. Talat Nasim ${ }^{1,2,6,7 *}$

Short Title: The BMPRII-ALK1-Bcl-xBcl-x axis in PAH

${ }^{1}$ Department of Medical and Molecular Genetics, King's College London, London, United Kingdom, ${ }^{2}$ School of Pharmacy and Medical Sciences, University of Bradford, Bradford, United Kingdom, ${ }^{3}$ Department of Pharmaceutical Technology, University of Dhaka, Bangladesh, ${ }^{4}$ Department of Pharmacognosy, Faculty of Pharmacy, Hacettepe University, 06100, Ankara, Turkey, ${ }^{5}$ Division of Respiratory Medicine, Department of Medicine, University of Cambridge, United Kingdom, ${ }^{6}$ National Institute for Health Research (NIHR), Biomedical Research Centre, Guy's and St. Thomas' NHS Foundation Trust and King's College London, London, United Kingdom, ${ }^{7}$ Centre for Health Agricultural and Socioeconomic Advancements (CHASA), Lalmonirhat, Bangladesh.

Correspondence can be addressed to

*Dr. M. T. Nasim

School of Pharmacy and Medical Sciences

University of Bradford

Bradford BD7 1DP

United Kingdom

Tel. 01274236076

Email.t.nasim@bradford.ac.uk 


\begin{abstract}
Pulmonary Arterial Hypertension (PAH) is a devastating cardiovascular disorder characterised by the remodelling of pre-capillary pulmonary arteries. The vascular remodelling observed in $\mathrm{PAH}$ patients results from excessive proliferation and apoptosis resistance of pulmonary arterial smooth muscle (PASMCs) and endothelial cells (PAECs). We have previously demonstrated that mutations in the type II receptor for bone morphogenetic protein (BMPRII) underlie the majority of the familial and inherited forms of the disease. We have further demonstrated that BMPRII deficiency promotes excessive proliferation and attenuates apoptosis in PASMCs, but the underlying mechanisms remain unclear. The major objective of this study is to investigate how BMPRII deficiency impairs apoptosis in PAH. Using multidisciplinary approaches, we demonstrate that deficiency in the expression of BMPRII impairs apoptosis by modulating the alternative splicing of the apoptotic regulator, $\mathrm{Bcl}-\mathrm{x}$ (B-cell lymphoma $\mathrm{X}$ ) transcripts: a finding observed in circulating leukocytes and lungs of $\mathrm{PAH}$ subjects, hypoxia-induced $\mathrm{PAH}$ rat lungs as well as in PASMCs and PAECs. BMPRII deficiency elicits cell specific effects: promoting the expression of $\mathrm{Bcl}-\mathrm{xL}$ transcripts in PASMCs whilst inhibiting it in ECs, thus exerting differential apoptotic effects in these cells. The pro-survival effect of BMPRII receptor is mediated through the activin receptor like kinase 1 (ALK1) but not the ALK3 receptor. Finally, we show that BMPRII interacts with the ALK1 receptor and pathogenic mutations in the BMPR2 gene abolish this interaction. Taken together, dysfunctional BMPRII responsiveness impairs apoptosis via the BMPRII-ALK1-Bcl-xL pathway in PAH. We suggest $\mathrm{Bcl}-\mathrm{xL}$ as a potential biomarker and druggable target.
\end{abstract}




\section{INTRODUCTION}

Pulmonary Arterial Hypertension (PAH) is a devastating and incurable cardiovascular disorder characterised by the remodelling of pre-capillary pulmonary arteries. The condition is characterised by abnormal proliferation and apoptosis resistance of pulmonary arterial smooth muscle cells (PASMCs), endothelial cells (PAECs) and fibroblasts, leading to elevated pulmonary artery pressure, right-heart failure, and premature death $(1,2)$.

Heterozygous loss of function mutations in the bone morphogenic protein type II receptor (BMPR2) gene (3) underlie the majority $(>80 \%)$ of familial and heritable PAH and can be identified in a substantial proportion ( 40\%) of isolated $\mathrm{PAH}$ cases $(3,4)$. We have determined that disease-associated nonsense mutations trigger degradation of the BMPR2 transcript via the nonsense-mediated decay (NMD) process. This contributes to a stoichiometric imbalance in the receptor complex and dysfunctional signalling (5). Furthermore, we have found a number of heterozygous mutations in SMAD1, SMAD4 and SMAD9 genes in European and Japanese cohorts, which were excluded for BMPR2 mutation. Each mutation impacts upon transcript integrity, reduces bone morphogenic protein (BMP) signalling, and diminishes expression of the Id1-3 genes (6). Recent investigations have identified novel mutations in BMP9, EIF2KA4, ATP13A3, AQP1 and SOX17 genes, but they represent an infrequent cause of the disease $(7,8)$. Furthermore, reduced BMPRII expression has been observed in non-genetic forms of PAH in humans (9) and animal models (10). These results imply that the impaired BMPRII pathway may cause susceptibility to abnormal vascular homeostasis leading to PAH.

A balance between pro- and anti-apoptotic factors determines cell fate. The B-cell lymphoma 2 (Bcl2) family proteins are well known for their roles in regulation of apoptosis. Bcl-2, Bcl-xL, Bcl-w proteins constitute the anti-apoptotic members of this family whilst Bax, Bid, Bad and $\mathrm{Bcl}-\mathrm{xS}$ proteins belong to the pro-apoptotic group. The expression of anti-apoptotic regulators such as the $\mathrm{Bcl} 2$ gene is increased in both sporadic and familial $\mathrm{PAH}$ lung tissues (11). A member of this family of genes is B-cell lymphoma $X(B c l-X)$, which generates both pro- (Bcl-xS) and anti-apoptotic (Bcl-xL) isoforms via alternative splicing (12). In normal PASMCs, BMP signalling downregulates the expression of $\mathrm{Bcl} 2$ (13). We and others have shown that SMAD-independent pathways such as p38MAPK and NF-KB are activated in experimental models of $\mathrm{PAH}$, and that these pathways have been shown to enhance the expression of Bcl-xL isoform (14), thereby exerting an anti-apoptotic phenotype. We have previously demonstrated that apoptosis is greatly reduced in mouse PASMCs harbouring the pathogenic BMPR2 ( $\mathrm{p} . \mathrm{R} 899 \mathrm{X}$ ) mutation and the BMPRII deficiency potentiates the transforming growth factor $\beta$ (TGF $\beta$ ) signalling pathway. TGF $\beta$ induces apoptosis in human $B$ cells by transcriptional activation of $\mathrm{Bcl}-\mathrm{xL}$ (15). Taken together, these observations indicate a relationship between BMP/TGF $\beta$ signalling pathways and the regulation of $\mathrm{Bcl} 2$ family of proteins. However, how dysfunctional BMPRII signalling regulates the alternative splicing of Bcl-x transcripts in PAH remains to be investigated.

We and others have demonstrated that in PASMCs isolated from PAH subjects (PAHPASMCs), the anti-proliferative and pro-apoptotic effects of BMPs (2, 4, 7 and 9), are greatly reduced (6,16-18). In vascular endothelial cells, BMP ligands elicit a pro-proliferative response (19). In addition, BMPs protect vascular and blood-derived endothelial cells from apoptosis (4) and this protection seems to be mediated by the BMPRII receptor, as inactivating mutations in the receptor trigger endothelial cell apoptosis (20). We have previously demonstrated that BMPRII deficiency elicits pro-proliferative and anti-apoptotic phenotype in PASMCs via the TGF $\beta$-associated kinase 1 (TAK1), but the underlying mechanisms by which apoptosis resistance is controlled in $\mathrm{PAH}$ remains unclear.

In this report, we have investigated the underlying mechanisms leading to apoptosis resistance in $\mathrm{PAH}$. We have shown that the expression of anti-apoptotic $\mathrm{Bcl}-\mathrm{xL}$ transcripts is 
greatly increased in the lungs and circulating leukocytes of $\mathrm{PAH}$ patients with and without BMPR2 mutations. The expression of $\mathrm{Bcl}-\mathrm{xL}$ transcripts is also increased in hypoxic PAH rat lungs and in PAH-PASMCs harbouring the BMPR2 (p.R899X) mutation. Selective inhibition of Bcl-xL protein by a small molecule agent induces apoptosis in PAH-PASMCs. In endothelial cells, siRNA knock down of either the BMPR2 or the ALK1 gene promotes endothelial cell apoptosis. Overexpression of the BMPRII receptor activates the expression of $\mathrm{Bcl}-\mathrm{xL}$ and inhibits caspase 3/7 activities. The pro-survival effect of BMPRII receptor is mediated through the ALK1 but not the ALK3 receptor. Finally, we have shown that BMPRII interacts with the ALK1 receptor and mutations in the BMPR2 gene, abolish this interaction and reduce BMP-responsive reporter activation. Taken together, these observations suggest that the BMPRII-ALK1-Bcl-xL pathway regulates cell-specific apoptosis in PAH. Whilst determination of the ratio of $\mathrm{Bcl}-\mathrm{xL}$ and $\mathrm{Bcl}-\mathrm{xS}$ transcripts offers the opportunity for a novel biomarker, targeting the BMPRII-Bcl-xL axis may provide a novel therapeutic intervention in $\mathrm{PAH}$.

\section{RESULTS}

The expression of anti-apoptotic Bcl-xL transcripts is increased in circulating leukocytes and lungs of PAH patients

Alternative splicing of the $\mathrm{Bcl}-\mathrm{x}$ gene, a key regulator of apoptosis, generates the proapoptotic (Bcl-xS) and anti-apoptotic (Bcl-xL) isoforms (Figure 1A) (12). To determine whether alternative splicing of $\mathrm{Bcl}-\mathrm{x}$ transcripts is altered in $\mathrm{PAH}$ patients, semi-quantitative PCR analyses were performed on circulating leukocytes of six PAH patients and seven control subjects. Out of the six PAH patients studied, five patients harboured mutations in the BMPR2 gene. The BMPR2 mutations were nonsense (p.L287X), frameshift (c.A796fsX6) and deletion (c.A497-503del, c.768+3delA), all of which are likely to introduce a premature termination codon into the reading frame. A substantial reduction in the pro-apoptotic transcript, Bcl-xS, and an increase in the anti-apoptotic Bcl-xL isoform were observed in $\mathrm{PAH}$ cases compared to control subjects (Figure 1B-C). We next determined the relationship between defective BMPRII signalling and Bcl-x splicing in lung tissues of a PAH patient who had undergone combined heart and lung transplantation. The PAH patient studied harboured a nonsense (p.T835X) BMPR2 mutation. Consistent with the leukocyte data, we observed significantly increased expression of the anti-apoptotic isoform Bcl-xL over Bcl-xS in PAH lungs compared with the control (Figure 1D-E). These results indicated that there might be a correlation between preferential expression of the anti-apoptotic Bcl-xL over the pro-apoptotic $\mathrm{Bcl}-\mathrm{xS}$ transcripts in PAH patients with and without BMPR2 mutations.

\section{BMPRII deficiency promotes the anti-apoptotic Bcl-xL expression in hypoxia-induced PAH rat lungs}

As we observed an increased $\mathrm{Bcl}-\mathrm{xL}$ expression in $\mathrm{PAH}$ cases who do not harbour a BMPR2 mutation, we were keen to determine whether the expression of $\mathrm{Bcl}-\mathrm{xL}$ was upregulated in a non-genetic PAH experimental model. Therefore, the hypoxia-induced rat model of PAH (17) was used to investigate the relationship between reduced levels of the BMPRII receptor and the alternative splicing of $\mathrm{Bcl}-\mathrm{x}$. Two weeks of chronic hypoxia reduced the level of BMPR2 expression (Figure 2A) and increased the ratio of $\mathrm{Bcl}-\mathrm{xL}$ to $\mathrm{Bcl}-\mathrm{xS}$ and $\mathrm{Bcl}-\mathrm{xL}$ to GAPDH in rat lung tissues (Figure 2B-D), confirming a link between BMPRII deficiency and preferential expression of the anti-apoptotic Bcl-xL transcripts.

\section{The expression of anti-apoptotic Bcl-xL transcripts is increased in both primary PAH- PASMCs and hTERT-PASMCs harbouring a pathogenic BMPR2 mutation}

Having observed an increased level of $\mathrm{Bcl}-\mathrm{xL}$ expression in $\mathrm{PAH}$ patient samples and in $\mathrm{PAH}$ rat lungs, we were keen to investigate alternative splicing of the $\mathrm{Bcl}-\mathrm{x}$ gene in cells 
including PASMCs and ECs, which are involved in the remodelling of small pulmonary arteries. We first investigated the expression of Bcl-x transcripts in human PASMCs. These cells were isolated from explanted lung samples from a $\mathrm{PAH}$ patient harbouring a pathogenic mutation (p.R899X) in the BMPR2 gene. PAH-PASMCs and commercially available wildtype PASMCs were grown in tissue culture plates until confluency and their total RNAs were isolated. Semi-quantitative PCR was carried out to determine the expression of Bcl-x transcripts. Low level expression of Bcl-x transcripts was observed in wild-type PASMCs whilst the expression of $\mathrm{Bcl}-\mathrm{xL}$ transcripts was significantly increased in PAH-PASMCs (Figure 3A-B). We further investigated the expression of Bcl-xL transcripts in PAH-PASMCs immortalized by the expression of human telomerase gene (hTERT) (Nasim et al., unpublished data). The expression of $\mathrm{Bcl}-\mathrm{xL}$ transcripts was also increased in these cells (Figure 3A-B).

\section{Dysregulated BMPRII-mediated signalling impairs caspase activity in PASMCs}

BMPRII mediated signalling elicits pro-apoptotic effect in PASMCs (17) . To determine the relationship between pro-apoptotic effects of BMPRII and the preferential expression of Bcl$\mathrm{xL}$ transcripts (Figure $3 \mathrm{C}$ ), we took advantage of PASMCs derived from knock-in (K-I) mice harbouring the PAH-associated BMPR2 nonsense mutation (p.R899X). These mice were asymptomatic at the age of three months but developed age-related $\mathrm{PAH}$ at the age of six months (4). PASMCs were isolated from asymptomatic wild-type (bmpr2 ${ }^{+/+}$) and mutant (bmpr2 ${ }^{\mathrm{R} 899 \mathrm{X}_{+}+-}$) mice and the rate of apoptosis was determined by measuring cysteinyl aspartate proteases (caspase) activity using commercially available kits (Promega) following manufacturer's instructions. Consistent with our previous observations, the basal activity level of caspases 3 and 7 was attenuated in mutant cells compared with wild-type (Supp Figure 1) (17). We earlier demonstrated that staurosporine (ST), a known inducer of apoptosis showed differential effects, with ST- induced caspase activity seemingly greater in mutant cells than wild-type (17). We further characterized the pro-apoptotic effect of BMP signalling on ST-induced apoptosis by stimulating the cells with BMP9 ligand (Figure 3D). In wild-type cells, the caspase activity was further increased following ligand stimulation, which is consistent with the previous finding of BMP-dependent caspase activation (21). The proapoptotic effect of BMP stimulation was absent in BMPRII deficient cells. In these cells, BMP9 inhibited staurosporine induced cell death in a dose dependent manner (Figure 3D).

\section{Selective inhibition of Bcl-xL by a chemical agent induces apoptosis in PAH-PASMCs}

We hypothesized that BMPRII dysfunction potentiates the apoptotic-resistant phenotype through the upregulation of $\mathrm{Bcl}-\mathrm{xL}$, and that selective inhibition of $\mathrm{Bcl}-\mathrm{xL}$ induces apoptosis (Figure 3E). We used PAH-PASMCs harbouring the BMPR2 (p.R899X) mutation as these cells showed reduced level of apoptosis compared with wild-type (17). PASMCs were treated with 2, 3 DCPE hydrochloride for 48 hours and the caspase activity was determined. The compound significantly increased apoptosis in PAH-PASMCs in a concentration dependent manner (Figure 3F). As expected, it also induced apoptosis in wild-type PASMCs.

\section{BMPRII-mediated signalling promotes the expression of Bcl-xL transcripts in PAECs and HEK293T cells}

Having characterised the expression of Bcl-xL transcripts in PASMCs, we then determined $\mathrm{Bcl}-\mathrm{x}$ splicing in PAECs following knock-down of either BMPRII or ALK1 receptors. siRNAs targeting either the BMPR2 or $A L K 1$ gene significantly inhibited the expression of $\mathrm{Bcl}-\mathrm{xL}$ transcripts (Figure 4A-B). qPCR analyses of BMPR2 and ALK1 transcripts showed reduced level of these transcripts in cells transfected with siRNAs compared with that of controls (Supp Figure 2A-B). Of note, little or no expression of Bcl-xS transcripts was observed in PAECs. Next, we determined the effect of BMPRII overexpression on Bcl-x expression. For this experiment, we selected the human embryonic kidney (HEK293T) cells as the transfection efficiency is higher in these cells compared with PASMCs and PAECs. Cells 
were co-transfected with a plasmid harbouring the wild-type BMPRII receptor. We found that the expression of $\mathrm{Bcl}-\mathrm{xL}$ transcripts was increased in cells overexpressed with the BMPRII receptor compared with the untreated control (Figure 4C-D). Whilst we found that HEK293T cells treated with BMP9 ligand $(10 \mathrm{ng} / \mathrm{ml})$ increased the level of Bcl-xL transcripts, the ligand elicited no discernible effect on the preferential expression of Bcl-x in PAECs (Supp Figure 3A-B).

\section{Knock down of either BMPRII or ALK1 promotes endothelial cell apoptosis}

As BMPRII mediated signalling has been shown to protect human PAECs from apoptosis (20), we used siRNAs against either BMPRII or ALK1 and determined their effect on endothelial cell apoptosis by measuring caspase 3/7 activities. Knock down of either BMPRII or ALK1 increased caspase 3/7 activities, indicating pro-survival roles of BMP signalling in PAECs (Figure 4E).

\section{BMPR2 mutations found in PAH patients reduce pro-survival effects}

We were interested to investigate the effect of a wide range of mutations identified in PAH patients on pro-survival activity. To investigate this, we employed HEK293T cells as in these cells BMPRII-mediated signalling increased the expression of pro-survival Bcl-xL isoform. The pro-survival effect of BMPRII-mediated signalling was investigated by transfecting HEK293T cells with plasmids harbouring either BMPRII wild-type or a wide range of mutant receptors (Figure 4F). Cell viability was measured using Cell-Titre Glo Cell Viability Assay Kit (Promega) following manufacturer's instructions. Cell viability was increased in cells transfected with the wild-type receptor suggesting a pro-survival role of BMPRII-mediated signalling in HEK293T cells (Figure 4G). In contrast, the cell viability was significantly reduced in cells transfected with the mutant p.C118W, p.D485G, p.N51K, p.S532X, pR899X and p.R899P plasmids, indicating that the pro-survival effects of BMPRII receptor are greatly reduced in the presence of pathogenic mutations (Figure 4G). However, cells transfected with the p.E503D mutant showed no discernible effects. Of note, we previously demonstrated that this mutation was capable of mediating BMP signalling at the level comparable to the wild-type receptor (5). Collectively, these data suggest that BMPR2 dysfunction elicits cell-specific effects. The receptor dysfunction induces anti-apoptotic effects in PASMCs whilst it exerts anti-survival effects in PAECs and HEK293 cells.

\section{BMP signalling inhibits caspase $3 / 7$ activities via the ALK1 receptor}

Having identified pro-survival effects of BMPRII-mediated signalling in both endothelial and HEK293T cells, we were keen to investigate the underlying mechanisms by which BMPRII regulates anti-apoptotic effects (Figure 5A). First, we investigated the effect of BMP signalling on apoptosis. Briefly, HEK293T cells were stimulated with BMP4 ligand $(10 \mathrm{ng} / \mathrm{ml})$ overnight in the presence of ST and the activities of caspase 3/7 activities were determined. We found that BMP4 stimulation reduced ST-induced caspase activities (Figure 5B). Next, the BMP signalling promoting activity of BMP4 ligand and BMPRII receptor was tested using the BMP-responsive 3GC2-Lux reporter assay (22) as previously described by us (5). HEK293T cells were stimulated with the ligand $(10 \mathrm{ng} / \mathrm{ml})$ at various time points $(30 \mathrm{mins}, 1 \mathrm{~h}$, $3 \mathrm{hrs}$, 5hrs, 7hrs, 9hrs and 24hrs) with and without BMPRII overexpression and their luciferase and $\beta$-galactosidase activities were determined. Reporter activation was observed after 7 hours of ligand stimulation and the highest activity was observed at the 24 hour time point (Supp Figures 4A-C). Together, these results indicate that the attenuation of caspase activities observed in these cells might be due to the activation of BMP signalling.

Next, we tested whether the anti-caspase effect of BMP signalling is mediated through the ALK3, ALK1 and BMPRII receptors. Overexpression of either BMPRII or type I receptors ALK3 and ALK1 individually, have no discernible effect on basal caspase activation (Figure 
5C). Interestingly, co-expression of ALK1 and BMPRII significantly inhibits both basal and ST-induced caspase activity HEK293T cells (Figure 5C-D and Supp Figure 5).

\section{Mutations in either ALK1 or BMPRII receptor impair the BMPRII-ALK1 pathway}

Since ALK1 has been shown to form a complex with BMPRII (23), we investigated whether both receptors work synergistically to regulate BMP signalling pathway. To do this, we used the BMP-responsive 3GC2-Lux reporter assay system to monitor BMP signalling (22). Overexpression of BMPRII alone and co-expression of BMPRII with ALK3 synergistically elevated the basal level of luciferase activity, which was consistent with our previous observations (5) (Figure 6A). Co-expression of BMPRII and ALK1 receptors generated reporter activity to a level comparable to that achieved by co-expression of BMPRII and ALK3 receptors, indicating that both BMPRII and ALK1 regulate BMP signalling in a synergistic manner (Figure 6A).

Having demonstrated that the BMPRII and ALK1 receptors work synergistically to activate the BMP signalling pathway, we then investigated the effects of ligands including BMP4 and BMP9 on BMPRII receptor (Figure 6B). We found that HEK293T cells co-expressing BMPRII and stimulated with either BMP4 or BMP9 showed increased reporter activation compared with cells expressing BMPRII alone (Figure 6B). Furthermore, we found BMP9 but not BMP4 ligand significantly increased ALK1-BMPRII-mediated reporter activation compared with cells transfected with BMPRII and stimulated with either BMP4 or BMP9 ligand (Supp Figures 6A-B). We previously showed that mutations in the BMPR2 gene significantly reduced BMPRII-ALK3-mediated reporter activation. Among the mutations investigated, the p.D485G mutant was unable to interact with either ALK3 or ALK6 receptor and failed to activate the BMP-responsive reporter in the absence and presence of ALK3 and ALK6 receptor overexpression and BMP4 ligand stimulation (5). In this study, we found that in the presence of this mutation, BMPRII-ALK1 mediated reporter activation was also significantly reduced both in the absence and presence of BMP9 stimulation (Figure $6 \mathrm{C}$ and Supp Figure 7A). Similarly, while testing the effect of ALK1 mutations (p.S333I and p.R111Q) identified in hereditary haemorrhagic telangiectasia (HHT) patients (24-26), we found that BMPRII-ALK1 mediated reporter activation was significantly reduced (Figure 6D). Furthermore, BMP9-stimulated reporter activation was significantly reduced in cells overexpressing ALK1 mutations (p. D179A, p.S333I and p.R111) compared with the wildtype receptor (Supp Figure 7B). Collectively, these data suggest that mutations in either the BMPRII or ALK1 receptor impinge upon the BMPRII-ALK1 pathway.

\section{Mutations found in the BMPR2 gene identified in PAH cases impair BMPRII-ALK1 interactions}

We previously showed that the BMPRII receptor interacts with both ALK3 and ALK6 receptors and pathogenic BMPR2 mutations impair these interactions (17). In this study, we first investigated whether BMPRII interacted with the ALK1 receptor and then determined the effect of BMPR2 mutations on BMPRII-ALK1 interactions. For this investigation, we employed our previously established cell-based protein-protein interactions assay, which was successfully used for determining the efficiency of interactions of BMPRII with ALK3 and ALK6 receptors $(5,27)$. The assay system was based on the mammalian version of yeast two hybrid screen (27). Briefly, the activation domain (AD) was fused with the intracellular part of the BMPRII receptor, whilst the ALK1 lacking the extracellular domain was fused with DNA binding domain (DBD). The dual-reporter was co-transfected with both the ALK1-DBD and BMPRII-AD. In the event of no interaction, the cells generate only the upstream $\beta$ galactosidase protein (Figure 7A). In the event of BMPRII-ALK1 interactions, both luciferase and $\beta$-galactosidase activities are generated.

Co-expression of BMPRII and ALK1 constructs generated both luciferase and $\beta$ galactosidase read outs indicating an interaction between these two proteins (Figure 7B). 
However, we found that the efficiency of interactions of BMPRII with ALK1 was 26-fold weaker compared with the interactions between BMPRII and ALK3 receptors. We next investigated the effects of a wide range of $B M P R 2$ mutations found in patients suffering from either PAH or congenital heart defects on BMPRII-ALK1 interactions. All mutations tested significantly impaired the efficiency of interactions between ALK1 and BMPRII proteins (Figure 7C).

\section{DISCUSSION}

The vascular remodelling observed in $\mathrm{PAH}$ lungs is caused by abnormal apoptosis of PASMCs and PAECs, but the underlying mechanisms by which apoptosis is controlled in $\mathrm{PAH}$ have remained elusive. Here, we report a novel mechanism which demonstrates that the dysregulated apoptosis in PAH is controlled via the BMPRII-Bcl-xL axis.

This study shows in a number of ways that BMPR2 haploinsufficiency modulates the preferential expression of the anti-apoptotic Bcl-xL over the pro-apoptotic Bcl-xS transcripts both in PAH patients and in an animal model. First, we found preferential expression of the anti-apoptotic $\mathrm{Bcl}-\mathrm{xL}$ transcripts in circulating leucocytes of $\mathrm{PAH}$ patients with and without BMPR2 mutations. Second, the increased expression of $\mathrm{Bcl}-\mathrm{xL}$ transcripts was also observed in lungs of a $\mathrm{PAH}$ patient who had undergone combined heart and lung transplantation. The BMPR2 mutations included in this study are nonsense, insertion, and deletion mutations, and hence transcripts harbouring these alleles are likely to be degraded through the nonsense-mediated decay (NMD) pathway, creating a state of haploinsufficiency (5). Finally, in the chronic hypoxic rat lungs which showed a diminished level of BMPR2 transcripts, the ratios of $\mathrm{Bcl}-\mathrm{xL}$ to $\mathrm{Bcl}-\mathrm{xS}$ and $\mathrm{Bcl}-\mathrm{xL}$ to GAPDH were increased. Consistent with our observations, elevated levels of $\mathrm{Bcl}-\mathrm{xL}$ protein were also found in pulmonary artery of chronic hypoxia treated rats with vascular remodelling (28).

Many signalling pathways such as p38MAPK, ERK1/2, JAK/STAT, TNF, NF-KB and PI3K are activated and/or dysregulated in $\mathrm{PAH}$ patients. Previous observations suggest that each of these pathways is capable of contributing to the preferential expression of $\mathrm{Bcl}-\mathrm{xL}$ transcripts. For example, ERK1/2 activates the p90RSK, which potentiates the transcription factor CREB and induces the expression of Bcl-xL and Bcl-2 transcripts $(29,30)$. Additionally, ECs derived from idiopathic PAH (IPAH) patients show elevated levels of phosphorylated ERK1/2 and Bcl-xL expression leading to apoptosis resistance (31). TNF- $\alpha$ has been shown to activate both pro-apoptotic and anti-apoptotic pathways. Whilst it induces apoptosis by activating caspase-8 and -10 , its anti-apoptotic activity is mediated via NF-kB, which induces the expression of anti-apoptotic Bcl-2 family of proteins (32-34). The PI3K/AKT pathway inhibits the expression of $\mathrm{Bcl}-\mathrm{xL}$ transcripts by inhibiting the activation of FoxO transcription factor $(35,36)$. These observations suggest that regulation of $\mathrm{Bcl}-\mathrm{xL}$ transcripts may also occur through a process that is independent of BMPR2 mutation.

Having established that the expression of $\mathrm{Bcl}-\mathrm{xL}$ transcripts increased in vivo, we then proved that BMPRII controls the expression of Bcl-xL transcripts. Firstly, we showed that in PAH-PASMCs harbouring the pathogenic BMPR2 (p.R899X) mutation, the expression of anti-apoptotic Bcl-xL transcripts was greatly increased, indicating that BMPRII dysfunction might potentiate resistance to apoptosis. Secondly, siRNA knock-down of either the BMPR2 or $A L K 1$ genes inhibited the expression of Bcl-xL in PAECs. Finally, overexpression of either BMPRII receptor or BMP9 stimulation increased the expression of Bcl-xL in HEK293T cells. These observations suggest cell-specific effects of BMPRII dysfunction on the preferential expression of $\mathrm{Bcl}-\mathrm{xL}$ transcripts. BMPRIl deficiency promotes the expression of $\mathrm{Bcl}-\mathrm{xL}$ transcripts in PASMCs, whilst inhibits it in ECs. Thus, the increased expression of $\mathrm{Bcl}-\mathrm{xL}$ transcripts may contribute to differential apoptotic effects in these cells.

Consistent with previous observations, we found that dysfunctional BMPRII signalling exerted anti-apoptotic phenotype in PASMCs whilst deficiency of this receptor led to 
apoptosis in PAECs $(4,17,23)$. We observed that overexpression of BMPRII receptor promoted cell survival and this effect was greatly reduced in the presence of pathogenic BMPR2 mutations. We provided extensive evidence that the pro-survival effect of BMPRII signalling was mediated through the ALK1 receptor and that these two receptors worked synergistically. Firstly, caspase activity was greatly reduced following co-expression of BMPRII with ALK1 but not with ALK3 receptor; activation of the BMP9/ALK1/BMPRII axis in endothelial cells showed anti-apoptotic phenotypes $(4,37)$. Secondly, cells co-expressed with BMPRII and ALK1, promoted BMP-responsive reporter activity and mutation either in BMPRII or in ALK1 impaired the reporter activation. Finally, we demonstrated that BMPRII interacted with the ALK1 receptor and in the event of pathogenic BMPR2 mutations, the efficiency of this interaction was greatly reduced. These observations support that stoichiometric imbalance in the BMPRII-ALK1 receptor complex may contribute to dysfunctional signalling leading to impaired apoptosis (5).

The involvement of anti-apoptotic Bcl-xL protein in developing apoptosis resistance in many cancers is well documented, but the underlying mechanisms by which preferential expression of the $\mathrm{Bcl}-\mathrm{xL}$ transcripts is regulated in $\mathrm{PAH}$ is not known. Based on our observations, we propose that either BMPR2 mutation or BMPRII receptor deficiency potentiates the expression of $\mathrm{Bcl}-\mathrm{xL}$ transcripts leading to apoptosis resistance in PASMCs (Figure 7D). In PAECs, BMPRII deficiency reduces the Bcl-xL expression leading to antisurvival effects. The pro-survival phenotype of PAECs is mediated via the BMPRII and ALK1 receptors. The ALK1 receptor works synergistically with the BMPRII and in the event of pathogenic BMPR2 mutations, the BMPRII-ALK1-mediated signalling is greatly reduced which increases the susceptibility of endothelial cells to undergo apoptosis but not sufficient to trigger PAH. A critical reduction in BMPRII-mediated signalling or the presence of an additional stimulus may trigger apoptosis-resistance of PASMCs leading to vascular remodelling.

Currently, neither any cure nor biomarker for PAH is known. Given the fact that antisense RNAs, small molecule agents such as fluoxetine and sodium nitroprusside and established drugs including ABT-263 (Navitoclax), which reduced the level of Bcl-xL protein reversed vascular remodelling in experimental models of PAH and adult $\mathrm{T}$ cell leukaemia indicate the potential of targeting this protein for therapeutic intervention $(38,39)$. Although increased Bcl$\mathrm{xL}$ expression was observed in preclinical and PAH cases, the major limitation to developing $\mathrm{Bcl}-\mathrm{xL}$ as a potential biomarker is that only a small number of patient samples were investigated in this study. Further epidemiological studies including various classes of PAH patients matched with healthy subjects together with analytical and clinical validations are required to determine whether $\mathrm{Bcl}-\mathrm{xL}$ can be used as a novel biomarker in $\mathrm{PAH}$.

In summary, we have demonstrated that BMPRII deficiency impairs apoptosis by modulating the alternative splicing of $\mathrm{Bcl}-\mathrm{x}$ transcripts, a finding observed in circulating leukocytes, lungs of PAH patients, hypoxic PAH rat lungs as well as in disease relevant human PASMCs and PAECs. Whilst BMPRII deficiency elicits anti-apoptotic effects in PASMCs, the receptor dysfunction induces pro-apoptotic responses in PAECs. The pro-survival effects of BMPRII are mediated through the ALK1 but not the ALK3 receptor in PAECs/HEK293T cells. BMPRII interacts with the ALK1 receptor and in the event of pathogenic BMPR2 mutations, this interaction is greatly reduced resulting in impaired signalling events. We propose that assessing $\mathrm{Bcl}-\mathrm{x}$ transcripts in patient samples offers the opportunity for developing a novel biomarker and that targeting the BMPRII-Bcl-xL axis may provide a novel therapeutic intervention in $\mathrm{PAH}$.

\section{MATERIALS AND METHODS}

Patient and control populations 
Ethical approval for these studies was obtained from Papworth Hospital ethical review committee (Ethics Ref 08-H0304-56+5) and Trent Multi-Centre Research Ethics Committee (MREC/02/4/003) for the human tissues used and patients gave the written informed consents. Control samples are healthy individuals, all of which have no mutations in the BMPR2 gene. Human lung tissues are from a PAH subject harbouring a BMPR2 mutation (p.835X) who underwent combined heart and lung transplantation. The control human lung RNAs are from a commercially available source (Clontech Laboratories, Inc.).

\section{Isolation of PASMCs}

Isolation of PASMCs was described elsewhere $(40,41)$. PAH-PASMCs were isolated from the proximal pulmonary arterial vessel segment $(5-8 \mathrm{~mm}$ diameter) obtained from the lung sample of a HPAH patient with a pathogenic BMPR2 mutation (p.R899X) undergoing lung transplantation. PASMCs of wild type $\left(\mathrm{bmpr}^{+/+}\right)$and knock-in mice harbouring the PAHassociated bmpr2 nonsense mutation (p.R899X) were derived from explants.

The luminal surface of the pulmonary artery was cut to open and endothelium was gently scrapped off using scalpel blade. The adjacent adventitia was stripped off and the medial explants were cut into 4-9 $\mathrm{mm}^{2}$ sections. These segments were then plated into T25 $\mathrm{cm}^{2}$ flasks and allowed to adhere. DMEM containing $20 \%$ FBS and antibiotic (Penicillin/Streptomycin)- antimycotic (Amphotericin B) was added to the flasks after 2 hours $(40,41)$. Cells were grown to confluency and used between passages $4-10$. The phenotype of the isolated cells was confirmed by immunostaining using antibody to smooth musclespecific $\alpha$-actin (Sigma, UK).

\section{RNA isolation, cDNA synthesis and reverse Transcriptase PCR (RT-PCR)}

RNAs were isolated from mammalian cells and circulating leukocytes using either TRIReagent (Sigma) or RNeasy Purification Kit (Qiagen, UK). cDNAs were synthesized using random primers and MMLV Reverse Transcriptase (Promega, UK) following manufacturer's protocol. Total lung tissue RNA was extracted using the TRIzol method (Invitrogen, Thermo Fisher Scientific, UK). $2 \mu \mathrm{g}$ RNA was then reverse transcribed using Thermoscript RT-PCR kits (Invitrogen, Thermo Fisher Scientific, UK). The PCR was carried out using Hi-Fidelity Extensor Master Mix (ABgene). Quantitative PCR for determining transcripts of bmpr2, and $\beta$-2 microglobulin ( $\beta$-2mg) were performed using TaqMan Gene Expression Assay (Applied Biosystems, UK) on either 7900HT Fast Real-Time PCR system (Applied Biosystems, UK) or Step One Plus (Applied Biosystems, UK) according to the manufacturer's protocol.

\section{Cell culture, transient transfection and enzymatic assay}

Cell culture and transfections were carried out as described elsewhere (5),(42),(43). GeneJammer transfection reagent (Stratagene, Agilent Technologies, USA) was used for transfection of the plasmids. The amount of plasmid DNAs transfected into the HEK293 and HEK293T cell lines varied from assay to assay (from $30 \mathrm{ng}$ to $1 \mu \mathrm{g}$ ). 24 hours after transfection, cells were treated with compounds in DMEM containing $0.1 \%$ FBS for an additional 24 hours. Cell lysate was prepared using $1 \mathrm{X}$ reporter lysis buffer (Promega, UK) as described earlier $(17,18)$ and Luciferase and $\beta$-galactosidase activities were determined with the Dual-light Reporter Assay (Applied Biosystems, UK) using either an ORION-II or an ORION-L Plate Luminometer (Berthold Technologies, UK) according to the manufacturer's protocols.

\section{Quantification of apoptosis and cell survival activity}

To determine the rate of apoptosis in HEK293, PASMCs and ECs, cells were seeded at $0.2 \times 10^{5}$ per well in a white 96 well plate as described elsewhere $(17,18)$. Twenty-four hours later, the medium was replaced by either fresh DMEM/0.1\% FBS alone or containing BMP9 
(1-10ng/ml) (R\&D Systems), BMP4 (10ng/ml) (R\&D Systems, UK), 2, 3 DCPE hydrochloride $(5-20 \mu \mathrm{M})$ (TOCRIS, Bioscience, UK) and assays were carried out 24 hours after the treatment. For induction of apoptosis, cells were treated with staurosporine (TOCRIS, Bioscience, UK) for overnight at a concentration of $1.25 \mu \mathrm{M}$. Apoptosis assays were carried out using Caspase-Glo ${ }^{\circledR}$ 3/7 Assay (Promega, UK) following manufacturer's instruction. Luminescence was recorded using either an ORION-II or an ORION-L Plate Luminometer (Berthold Technologies, UK) at 30 and 60 minutes intervals. The cell survival activity was determined using CellTiter-Glo Cell Viability Assay (Promega, UK).

\section{Short interfering RNA (siRNA)-mediated knock-down of ALK1 and BMPR2 genes}

siGENOME SMART pool siRNAs (Dharmacon) were used to knock down ALK1 and BMPR2 genes. The siGENOME SMARTpool is a mixture of 4 siRNAs, all designed to target different regions of the single gene of interest. PAECs were transfected with siRNAs either in 96 well plate $\left(1 \times 10^{4}\right)$ or 6 -well plate $\left(1 \times 10^{6}\right)$ using Dharmafect 1 (Dharmacon, USA) following manufacturer's protocol and incubated for 72 hours as previously described (43).

\section{Generation of constructs for protein-protein interactions assay}

The coding sequence of human ALK1 (accession number BC017715) lacking the first amino acid was cloned into BamHI and Xbal sites of pTN111 vector (27). The resulting plasmid contains a N-terminal DNA binding domain (DBD) adjacent to the human ALK1, the fidelity of which was verified by restriction analyses and sequencing. Efficiency of protein-protein interactions between ALK1 and BMPRII in mammalian cells was determined as previously reported (https://www.nature.com/protocolexchange/protocols/261). In brief the intracellular domain of BMPR2 was fused with VP-16 activation domain (5) whilst ALK1 was fused with a DBD. Plasmids encoding both fusion proteins were transfected into HEK293T cells together with the pTN114 dual reporter plasmid (5). In the event of an interaction both reporter proteins will be generated with the ratio of reporter activities producing a measure of the efficiency of protein-protein interactions.

Details of the other expression constructs used in this study are available upon request.

\section{Statistics}

Statistical analysis was performed following paired Student's t-test. Comparison of multiple means was carried out using ANOVA followed by Tukey's post hoc test.

\section{ACKNOWLEDGEMENTS}

The cDNA of normal and hypoxic rat lungs were generous gifts from Prof. Lan Zhao (Imperial College London). The authors wish to thank Ms Bethan Jones, Ms Rebeca Randall (King's College London) and Mr Rhys Wardman (Bradford) for valuable technical assistance.

This work was supported by a fellowship (awarded to MTN) from the Department of Health via the NIHR Comprehensive Biomedical Research Centre award to Guy's \& St Thomas' NHS Foundation Trust in partnership with King's College London, Heptagon Life Science Proof of Concept Fund (grant KCL24 to MTN), the Great Britain Sasakawa Foundation (grant B70 to MTN), the Royal Society (grant 43049 to MTN), the Medical Research Council (grant G900865 to RCT, MTN and NWM) and the University of Bradford (grants 003200 , 66006/001NAS and DH005 to MTN). NS and MYB were supported by scholarships from the Commonwealth Scholarship Commission, UK and Scientific and Technological Research Council of Turkey (TUBITAK), respectively.

\section{COMPETING INTERESTS}


A patent application has been filed.

\section{REFERENCES}

1. Morrell, N.W., Adnot, S., Archer, S.L., Dupuis, J., Jones, P.L., MacLean, M.R., McMurtry, I.F., Stenmark, K.R., Thistlethwaite, P.A., Weissmann, N. et al. (2009) Cellular and molecular basis of pulmonary arterial hypertension. J Am Coll Cardiol, 54, S20-31.

2. Gaine, S.P. and Rubin, L.J. (1998) Primary pulmonary hypertension. Lancet, 352 , 719-725.

3. Lane, K.B., Machado, R.D., Pauciulo, M.W., Thomson, J.R., Phillips, J.A., 3rd, Loyd, J.E., Nichols, W.C. and Trembath, R.C. (2000) Heterozygous germline mutations in BMPR2, encoding a TGF-beta receptor, cause familial primary pulmonary hypertension. The International PPH Consortium. Nat Genet, 26, 81-84.

4. Long, L., Ormiston, M.L., Yang, X., Southwood, M., Graf, S., Machado, R.D., Mueller, M., Kinzel, B., Yung, L.M., Wilkinson, J.M. et al. (2015) Selective enhancement of endothelial BMPR-II with BMP9 reverses pulmonary arterial hypertension. Nat Med, 21, 777785.

5. Nasim, M.T., Ghouri, A., Patel, B., James, V., Rudarakanchana, N., Morrell, N.W. and Trembath, R.C. (2008) Stoichiometric imbalance in the receptor complex contributes to dysfunctional BMPR-II mediated signalling in pulmonary arterial hypertension. Hum $\mathrm{Mol}$ Genet, 17, 1683-1694.

6. Nasim, M.T., Ogo, T., Ahmed, M., Randall, R., Chowdhury, H.M., Snape, K.M., Bradshaw, T.Y., Southgate, L., Lee, G.J., Jackson, I. et al. (2011) Molecular genetic characterization of SMAD signaling molecules in pulmonary arterial hypertension. Hum Mutat, 32, 1385-1389.

7. Graf, S., Haimel, M., Bleda, M., Hadinnapola, C., Southgate, L., Li, W., Hodgson, J., Liu, B., Salmon, R.M., Southwood, M. et al. (2018) Identification of rare sequence variation underlying heritable pulmonary arterial hypertension. Nature communications, 9, 1416.

8. Hadinnapola, C., Bleda, M., Haimel, M., Screaton, N., Swift, A., Dorfmuller, P., Preston, S.D., Southwood, M., Hernandez-Sanchez, J., Martin, J. et al. (2017) Phenotypic Characterization of EIF2AK4 Mutation Carriers in a Large Cohort of Patients Diagnosed Clinically With Pulmonary Arterial Hypertension. Circulation, 136, 2022-2033.

9. Atkinson, C., Stewart, S., Upton, P.D., Machado, R., Thomson, J.R., Trembath, R.C. and Morrell, N.W. (2002) Primary pulmonary hypertension is associated with reduced pulmonary vascular expression of type II bone morphogenetic protein receptor. Circulation, 105, 1672-1678.

10. Long, L., Crosby, A., Yang, X., Southwood, M., Upton, P.D., Kim, D.K. and Morrell, N.W. (2009) Altered bone morphogenetic protein and transforming growth factor-beta signaling in rat models of pulmonary hypertension: potential for activin receptor-like kinase-5 inhibition in prevention and progression of disease. Circulation, 119, 566-576.

11. Geraci, M.W., Moore, M., Gesell, T., Yeager, M.E., Alger, L., Golpon, H., Gao, B., Loyd, J.E., Tuder, R.M. and Voelkel, N.F. (2001) Gene expression patterns in the lungs of patients with primary pulmonary hypertension: a gene microarray analysis. Circ Res, 88, 555-562.

12. Sugimori, K., Matsui, K., Motomura, H., Tokoro, T., Wang, J., Higa, S., Kimura, T. and Kitajima, I. (2005) BMP-2 prevents apoptosis of the N1511 chondrocytic cell line through PI3K/Akt-mediated NF-kappaB activation. J Bone Miner Metab, 23, 411-419.

13. Zhang, S., Fantozzi, I., Tigno, D.D., Yi, E.S., Platoshyn, O., Thistlethwaite, P.A., Kriett, J.M., Yung, G., Rubin, L.J. and Yuan, J.X. (2003) Bone morphogenetic proteins induce apoptosis in human pulmonary vascular smooth muscle cells. Am J Physiol Lung Cell Mol Physiol, 285, L740-754.

14. Konig, H.G., Kogel, D., Rami, A. and Prehn, J.H. (2005) TGF- $\beta 1$ activates two distinct type I receptors in neurons: implications for neuronal NF-\{kappa\}B signaling. $J$ Cell Biol, 168, 1077-1086. 
15. Spender, L.C., O'Brien, D.I., Simpson, D., Dutt, D., Gregory, C.D., Allday, M.J., Clark, L.J. and Inman, G.J. (2009) TGF-beta induces apoptosis in human B cells by transcriptional regulation of BIK and BCL-XL. Cell Death Differ, 16, 593-602.

16. Morrell, N.W., Yang, X., Upton, P.D., Jourdan, K.B., Morgan, N., Sheares, K.K. and Trembath, R.C. (2001) Altered growth responses of pulmonary artery smooth muscle cells from patients with primary pulmonary hypertension to transforming growth factor-beta(1) and bone morphogenetic proteins. Circulation, 104, 790-795.

17. Nasim, M.T., Ogo, T., Chowdhury, H.M., Zhao, L., Chen, C.N., Rhodes, C. and Trembath, R.C. (2012) BMPR-II deficiency elicits pro-proliferative and anti-apoptotic responses through the activation of TGF $\beta$-TAK1-MAPK pathways in PAH. Hum Mol Genet, 21, 2548-2558.

18. Ogo, T., Chowdhury, H.M., Yang, J., Long, L., Li, X., Torres Cleuren, Y.N., Morrell, N.W., Schermuly, R.T., Trembath, R.C. and Nasim, M.T. (2013) Inhibition of overactive transforming growth factor- $\beta$ signaling by prostacyclin analogs in pulmonary arterial hypertension. Am J Respir Cell Mol Biol, 48, 733-741.

19. Valdimarsdottir, G., Goumans, M.J., Rosendahl, A., Brugman, M., Itoh, S., Lebrin, F., Sideras, P. and ten Dijke, P. (2002) Stimulation of Id1 expression by bone morphogenetic protein is sufficient and necessary for bone morphogenetic protein-induced activation of endothelial cells. Circulation, 106, 2263-2270.

20. Teichert-Kuliszewska, K., Kutryk, M.J., Kuliszewski, M.A., Karoubi, G., Courtman, D.W., Zucco, L., Granton, J. and Stewart, D.J. (2006) Bone morphogenetic protein receptor2 signaling promotes pulmonary arterial endothelial cell survival: implications for loss-offunction mutations in the pathogenesis of pulmonary hypertension. Circ Res, 98, 209-217.

21. Lagna, G., Nguyen, P.H., Ni, W. and Hata, A. (2006) BMP-dependent activation of caspase -9 and caspase- 8 mediates apoptosis in pulmonary artery smooth muscle cells. Am J Physiol Lung Cell Mol Physiol, 291, L1059-1067.

22. Ishida, W., Hamamoto, T., Kusanagi, K., Yagi, K., Kawabata, M., Takehara, K., Sampath, T.K., Kato, M. and Miyazono, K. (2000) Smad6 is a Smad1/5-induced smad inhibitor. Characterization of bone morphogenetic protein-responsive element in the mouse Smad6 promoter. J Biol Chem, 275, 6075-6079.

23. Scharpfenecker, M., van Dinther, M., Liu, Z., van Bezooijen, R.L., Zhao, Q., Pukac, L., Lowik, C.W. and ten Dijke, P. (2007) BMP-9 signals via ALK1 and inhibits bFGF-induced endothelial cell proliferation and VEGF-stimulated angiogenesis. J Cell Sci, 120, 964-972.

24. Trembath, R.C., Thomson, J.R., Machado, R.D., Morgan, N.V., Atkinson, C., Winship, I., Simonneau, G., Galie, N., Loyd, J.E., Humbert, M. et al. (2001) Clinical and molecular genetic features of pulmonary hypertension in patients with hereditary hemorrhagic telangiectasia. N Engl J Med, 345, 325-334.

25. Trembath, R.C. (2001) Mutations in the TGF- $\beta$ type 1 receptor, ALK1, in combined primary pulmonary hypertension and hereditary haemorrhagic telangiectasia, implies pathway specificity. J Heart Lung Transplant, 20, 175.

26. Harrison, R.E., Flanagan, J.A., Sankelo, M., Abdalla, S.A., Rowell, J., Machado, R.D., Elliott, C.G., Robbins, I.M., Olschewski, H., McLaughlin, V. et al. (2003) Molecular and functional analysis identifies ALK-1 as the predominant cause of pulmonary hypertension related to hereditary haemorrhagic telangiectasia. J Med Genet, 40, 865-871.

27. Nasim, M.T. and Trembath, R.C. (2005) A dual-light reporter system to determine the efficiency of protein-protein interactions in mammalian cells. Nucleic Acids Res, 33, e66.

28. Suzuki, Y.J., Nagase, H., Wong, C.M., Kumar, S.V., Jain, V., Park, A.-M. and Day, R.M. (2007) Regulation of Bcl-xL Expression in Lung Vascular Smooth Muscle. American Journal of Respiratory Cell and Molecular Biology, 36, 678-687.

29. Xiang, H., Wang, J. and Boxer, L.M. (2006) Role of the cyclic AMP response element in the bcl-2 promoter in the regulation of endogenous $\mathrm{Bcl}-2$ expression and apoptosis in murine B cells. Mol Cell Biol, 26, 8599-8606.

30. Shabestari, R.M., Safa, M., Alikarami, F., Banan, M. and Kazemi, A. (2017) CREB knockdown inhibits growth and induces apoptosis in human pre-B acute lymphoblastic 
leukemia cells through inhibition of prosurvival signals. Biomedicine \& pharmacotherapy $=$ Biomedecine \& pharmacotherapie, 87, 274-279.

31. Tu, L., Dewachter, L., Gore, B., Fadel, E., Dartevelle, P., Simonneau, G., Humbert, M., Eddahibi, S. and Guignabert, C. (2011) Autocrine Fibroblast Growth Factor-2 Signaling Contributes to Altered Endothelial Phenotype in Pulmonary Hypertension. American Journal of Respiratory Cell and Molecular Biology, 45, 311-322.

32. Kasof, G.M., Lu, J.J., Liu, D., Speer, B., Mongan, K.N., Gomes, B.C. and Lorenzi, M.V. (2001) Tumor necrosis factor-alpha induces the expression of DR6, a member of the TNF receptor family, through activation of NF-kappaB. Oncogene, 20, 7965-7975.

33. Feng, B., Cheng, S., Hsia, C.Y., King, L.B., Monroe, J.G. and Liou, H.C. (2004) NFkappaB inducible genes $\mathrm{BCL}-\mathrm{X}$ and cyclin $\mathrm{E}$ promote immature B-cell proliferation and survival. Cell Immunol, 232, 9-20.

34. Dai, Y., Desano, J., Tang, W., Meng, X., Meng, Y., Burstein, E., Lawrence, T.S. and $\mathrm{Xu}$, L. (2010) Natural proteasome inhibitor celastrol suppresses androgen-independent prostate cancer progression by modulating apoptotic proteins and NF-kappaB. PLoS One, 5, e14153.

35. Qian, J., Zou, Y., Rahman, J.S., Lu, B. and Massion, P.P. (2009) Synergy between phosphatidylinositol 3-kinase/Akt pathway and $\mathrm{Bcl}-\mathrm{xL}$ in the control of apoptosis in adenocarcinoma cells of the lung. Mol Cancer Ther, 8, 101-109.

36. Zhang, X., Zhuang, T., Liang, Z., Li, L., Xue, M., Liu, J. and Liang, H. (2017) Breast cancer suppression by aplysin is associated with inhibition of PI3K/AKT/FOXO3a pathway. Oncotarget, 8, 63923-63934.

37. David, L., Mallet, C., Mazerbourg, S., Feige, J.J. and Bailly, S. (2007) Identification of BMP9 and BMP10 as functional activators of the orphan activin receptor-like kinase 1 (ALK1) in endothelial cells. Blood, 109, 1953-1961.

38. Zhang, M., Mathews Griner, L.A., Ju, W., Duveau, D.Y., Guha, R., Petrus, M.N., Wen, B., Maeda, M., Shinn, P., Ferrer, M. et al. (2015) Selective targeting of JAK/STAT signaling is potentiated by $\mathrm{Bcl}-\mathrm{xL}$ blockade in IL-2-dependent adult T-cell leukemia. Proceedings of the National Academy of Sciences, 112, 12480.

39. Montero, J. and Letai, A. (2018) Why do BCL-2 inhibitors work and where should we use them in the clinic? Cell Death and Differentiation, 25, 56-64.

40. Long, L., MacLean, M.R., Jeffery, T.K., Morecroft, I., Yang, X., Rudarakanchana, N., Southwood, M., James, V., Trembath, R.C. and Morrell, N.W. (2006) Serotonin increases susceptibility to pulmonary hypertension in BMPR2-deficient mice. Circulation research, 98, 818-827.

41. Morrell, N.W., Upton, P.D., Kotecha, S., Huntley, A., Yacoub, M.H., Polak, J.M. and Wharton, J. (1999) Angiotensin II activates MAPK and stimulates growth of human pulmonary artery smooth muscle via AT1 receptors. American Journal of Physiology-Lung Cellular and Molecular Physiology, 277, L440-L448.

42. Nasim, M.T. and Eperon, I.C. (2006) A double-reporter splicing assay for determining splicing efficiency in mammalian cells. Nature Protocols, 1, 1022-1028.

43. Chowdhury, H.M., Siddiqui, M.A., Kanneganti, S., Sharmin, N., Chowdhury, M.W. and Nasim, M.T. (2018) Aminoglycoside-mediated promotion of translation readthrough occurs through a non-stochastic mechanism that competes with translation termination. Hum Mol Genet, 27, 373-384.

\section{FIGURE LEGENDS}

\section{Figure 1}

Increased expression of $\mathrm{Bcl}-\mathrm{xL}$ transcripts in circulating leukocytes and lungs of $\mathrm{PAH}$ patients. (A) Alternative splicing of the Bcl-x gene. Selection of the upstream 5' splice site (5'ss) generates the anti-apoptotic Bcl-xL long isoform, while the downstream 5' splice site produces the pro-apoptotic short isoform, Bcl-xS. (B) Reverse transcriptase polymerase 
chain reaction (RT-PCR) analysis of $\mathrm{Bcl}-\mathrm{xS}$ and $\mathrm{Bcl}-\mathrm{xL}$ transcripts derived from circulating leukocytes of PAH patients with and without BMPR2 mutations. Controls 1-6 are RNAs derived from healthy subjects whilst Control 7 is commercially available RNA (Clontech). (C) Quantification of the RT-PCR image. (D) RT-PCR analysis of Bcl-x transcripts in human lung tissue from a PAH subject harbouring a BMPR2 mutation ( $\mathrm{p} .835 \mathrm{X}$ ) who underwent combined heart and lung transplantation. The control lung RNAs are from a commercially available source (Clontech). (E) Quantification of RT-PCR by image analysis. The mean densities of bands derived from three independent experiments are shown. ${ }^{* *} P<0.01,{ }^{* *} P<0.001$ compared with control as indicated.

\section{Figure 2}

Determination of the alternative splicing of $\mathrm{Bcl}-\mathrm{x}$ pre-mRNA in hypoxic $\mathrm{PAH}$ rat lungs. $(\mathrm{A})$ Quantification of the BMPR2 transcript relative to $\beta$-2-microglobulin (b2mg) in hypoxic rat lungs by quantitative PCR. (B) As in Figure 1D, with lung samples derived from normoxic and hypoxic rats $(n=6)$. (C) Quantification of the Bcl-xL vs Bcl-xS ratio of RT-PCR. (D) Quantification of the relative $\mathrm{Bcl}-\mathrm{xL}$ vs GAPDH ratio of $\mathrm{RT}-\mathrm{PCR}$. ${ }^{* *} \mathrm{P}<0.01$ compared with normoxia.

\section{Figure 3}

BMPR2 mutation impairs apoptosis through up-regulating the expression of $\mathrm{Bcl}-\mathrm{xL}$ transcripts in PASMCs. (A) Determination of the alternative splicing of $\mathrm{Bcl}-\mathrm{x}$ pre-mRNA in human PASMCs. RT-PCR analysis of Bcl-x transcripts in human PASMCs from a PAH subject harbouring the BMPR2 mutation (p.R899X). The hTERT-PAH-PASMCs are the p.R899X-PAH PASMCs which were immortalized with the expression of catalytic subunit of human telomerase (hTERT) gene (Nasim et al, unpublished data). (B) Quantification of RTPCR $(n=4)$. (C) Diagram depicting the roles of $\mathrm{Bcl}-\mathrm{xL}$ and $\mathrm{Bcl}-\mathrm{xS}$ isoforms in apoptosis. (D) Differential effects of BMP9 ligand on apoptosis as determined by caspase $3 / 7$ activities in PASMCs derived from wild-type and mutant mice harbouring the pathogenic BMPR2 mutation (p.R899X) $(n=6)$. Apoptosis was induced by the established chemical staurosporine (ST, $1.25 \mu \mathrm{M}) .{ }^{* *} \mathrm{P}<0.01,{ }^{* *} \mathrm{P}<0.001$ compared with cells treated with ST only. (E) Diagram depicting the role 2,3 DCPE hydrochloride (TOCRIS), which selectively inhibits the activity of $\mathrm{Bcl}-\mathrm{xL}$ isoforms on apoptosis. (F) Selected inhibition of $\mathrm{Bcl}-\mathrm{xL}$ by 2,3 DCPE compound induces apoptosis in PAH-PASMCs in a dose-dependent manner $(n=4)$. Concentrations of the BMP9 ligand and DCPE compound are indicated below graphs. ${ }^{* * *} \mathrm{P}<0.001$ compared with untreated cells. Data are presented as mean \pm SEM from 3-6 independent experiments.

\section{Figure 4}

Pro-survival effects of BMPRII is mediated through $\mathrm{Bcl}-\mathrm{xL}$ and pathogenic BMPR2 mutations impair the pro-survival activity. (A) Either BMPRII or ALK1 down-regulates the expression of $\mathrm{Bcl}-\mathrm{xL}$ transcripts in PAECs. RT-PCR analysis of Bcl-x transcripts in human PAECs transfected with $30 \mathrm{nM}$ of siRNAs targeting either the BMPR2 or ALK1 gene. Cells were harvested 48 hours after siRNA transfection. (B) Quantification of RT-PCR $(n=4)$. (C) RTPCR analysis of $\mathrm{Bcl}-\mathrm{x}$ transcripts in HEK293T cells either transfected with a construct containing the BMPR2 gene or stimulated with BMP9 $(10 \mathrm{ng} / \mathrm{ml})$ ligand. (D) Quantification of RT-PCR $(n=4)$. (E) Either BMPRII or ALK1 deficiency by means of siRNA knock-down promotes apoptosis in PAECs as determined by caspase $3 / 7$ activities $(n=9)$. Cells were treated with siRNAs for 48 hours. (F) Diagram of the BMPRII domain structure depicting the ligand binding (LB), transmembrane (TM), kinase (KD) and C-terminal extension (CTD). The numbers below indicating relative amino acids, whilst the mutations tested are indicated above. (G) Mutations in the BMPR2 gene identified in PAH cases impair cell survival as determined by the Cell-titre Glow Cell Viability Assay (Promega) $(n=8)$. HEK293T cells were transfected either with the wild-type or mutant BMPRII receptors, ALK1 or ALK3 receptor 
and the relative cell viability was determined. The value derived from untreated control cells was set as 100. ${ }^{* *} \mathrm{P}<0.001$ compared with mock transfected cells, NS-non significant. Data are presented as mean \pm SEM from 3-6 independent experiments.

\section{Figure 5}

BMP signalling inhibits apoptosis via the BMPRII-ALK1-mediated pathway. (A) Diagram depicting the effect of BMP signalling cascade on caspase 3/7 activities. (B) BMP signalling inhibits apoptosis in HEK293T cells $(n=4)$ as determined by the Caspase-Glo 3/7 Assay (Promega). Cells treated with apoptosis-inducing agent staurosporine $(1.25 \mu \mathrm{M})$ and stimulated with BMP4 ligand $(10 \mathrm{ng} / \mathrm{ml})$ for 16 hours. BMPRII receptor inhibits both basal (C) and (D) staurosporine-induced apoptosis through the ALK1 receptor $(n=4)$. HEK293T cells transfected with either BMPRII, ALK1 and ALK3 receptors alone or BMPRII in combination with ALK1 and ALK3 receptors. Apoptosis was induced by treating the cells with staurosporine $(1.25 \mu \mathrm{M})$ for 16 hours $(D) .{ }^{* \star *} P<0.001$ compared with untreated $(B)$, BMPR-II overexpressed (C) and ST-induced (D) cells. Data are presented as mean \pm SEM from 3-6 independent experiments.

\section{Figure 6}

Mutations in either BMPRII or ALK1 receptors impair the BMPRII-ALK1-mediated signalling. (A) The efficiency of BMPRII-ALK1 signalling is comparable to that of BMPRII-ALK3 as determined by the BMP-responsive 3GC2-Lux reporter assay $(n=8)$. HEK293T cells transfected with the reporter plasmids together with BMPRII, ALK1, ALK3 and ALK6 receptors. (B) Promotion of BMPRII-mediated signalling by BMP4 and BMP9 ligands. HEK293T cells transfected with the reporter plasmids together with BMPRII and stimulated with either BMP4 $(10 \mathrm{ng} / \mathrm{ml})$ or BMP9 $(10 \mathrm{ng} / \mathrm{ml})$ ligands for overnight $(\mathrm{n}=8)$. (C) Mutation in the kinase domain of BMPRII receptor (p.D485G) significantly reduced BMPRII-ALK1mediated reporter activation. HEK293T cells transfected in combination with either wild-type or mutant BMPRII receptor with and without ALK1 $(n=8)$. (D) As $(C)$, cells transfected in combination with wild-type and mutant ALK1 receptor with and without BMPRII $(n=6)$. The luc-gal activity of the untreated control cells was set as 100 . Data are presented as mean \pm SEM from 3-6 independent experiments. ${ }^{* * *} \mathrm{P}<0.001$ compared with either untreated or as indicated.

\section{Figure 7}

Interaction of ALK1 and BMPRII determined by mammalian two hybrid protein-protein interaction assay (27). (A) Outline of the BMPRII-ALK1 interactions assay, which is based on our previously established mammalian version of yeast two-hybrid screen (27). The assay was developed in such that in the event of no interaction, only $\beta$-gal protein will be produced. An interaction between BMPRII and ALK1 generates both $\beta$-gal and luciferase proteins. (B) The efficiency of the interaction of BMPR-II with either ALK3 or ALK1. HEK293T cells transfected with plasmids encoding BMPRII fused to the activation domain (BMPRII-AD) and ALK1 fused to the DNA binding domain (ALK1-DBD) compared to reporter alone (TN114). The efficiency of the interaction between BMPRII and ALK1 was set as 100 ( $n=8)$. (C) Mutations in the BMPR2 gene identified in both familial and sporadic $\mathrm{PAH}$ cases significantly reduce BMPRII-ALK1 interactions $(n=10)$. As $(B)$, cells were co-transfected in combination with either wild-type or mutant BMPR-II receptor together with ALK1-DBD and pTN114 reporter. The relative luc-gal ratio in cells overexpressing mutant BMPRII and ALK1 compared to the wild-type BMPRII receptor. Data are presented as mean \pm SEM from 3-6 independent experiments. SV40- SV40 promoter, D/A unit- deactivation/activation unit for downstream transcription (27). ${ }^{* *} \mathrm{P}<0.001$ compared with reporter transfected with BMPR-II$A D$ and ALK1-DBD plasmids. AD indicates activation domain; DBD, DNA-binding domain. (D) Model depicting the regulation of apoptosis resistance in PAH. In PASMCs, either $B M P R 2$ mutations or BMPRII receptor deficiency potentiate the expression of $\mathrm{Bcl}-\mathrm{xL}$ 
transcripts leading to apoptosis resistance. In contrast, in PAECs, the receptor deficiency reduces the $\mathrm{Bcl}-\mathrm{xL}$ expression leading to anti-survival effects. The pro-survival phenotype of PAECs is mediated via the BMPRII and ALK1 receptors. Both ALK1 and ALK3 receptors work synergistically with the BMPRII and in the event of pathogenic BMPR2 mutations, the efficiency of interactions of BMPRII with type I receptors is greatly reduced $(5,17)$ which increases the susceptibility of PASMCs and PAECs to undergo impaired apoptotic pathway but not sufficient to trigger $\mathrm{PAH}$. The presence of an additional stimulus may further exacerbate the apoptosis-resistance process leading to vascular remodelling. Thus, the Bcl$\mathrm{x}$ gene may represent a potential biomarker and druggable target for $\mathrm{PAH}$. Straight arrows indicate activation; T-shapped line indicates inhibition. 


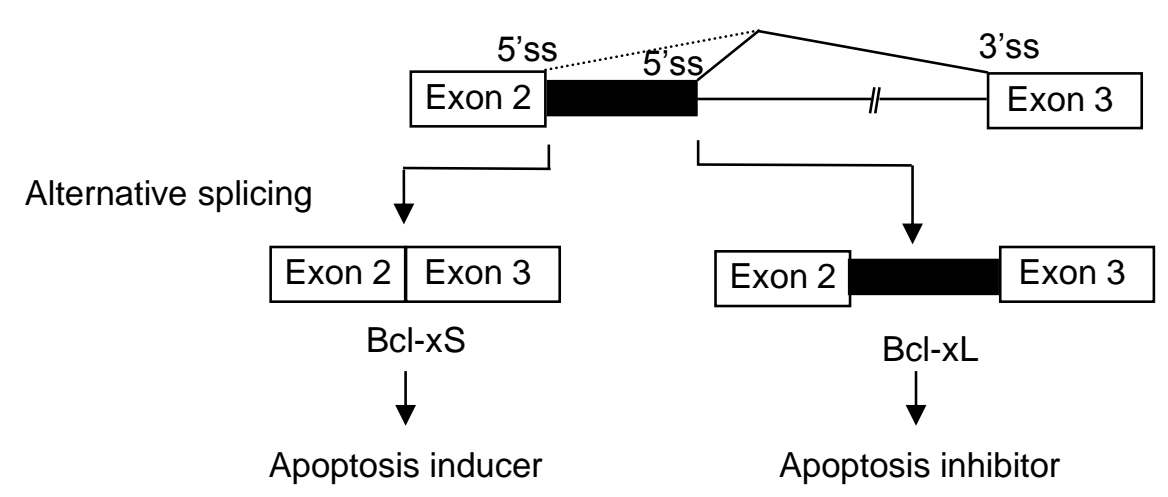

Figure 1

D

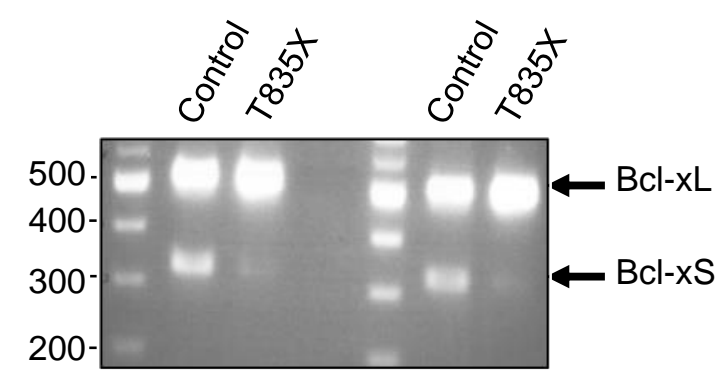

C

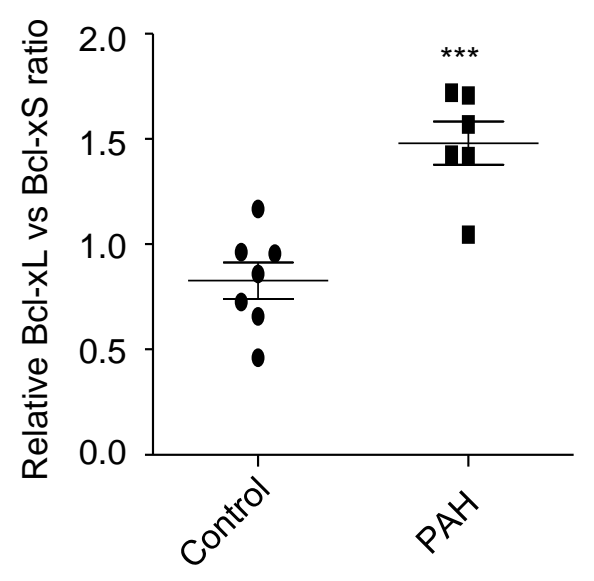

E

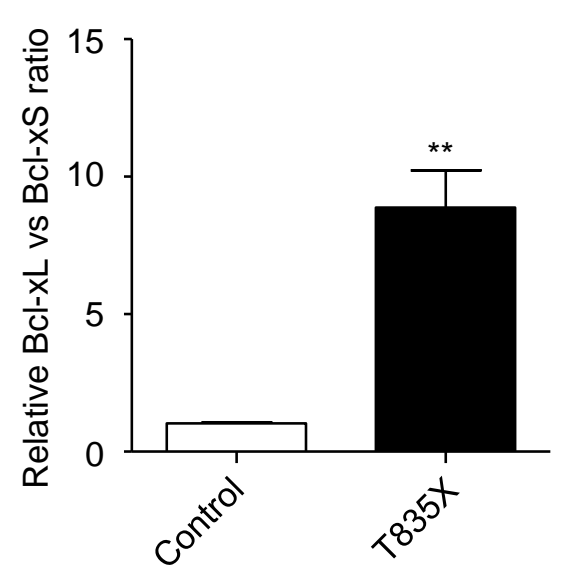


A

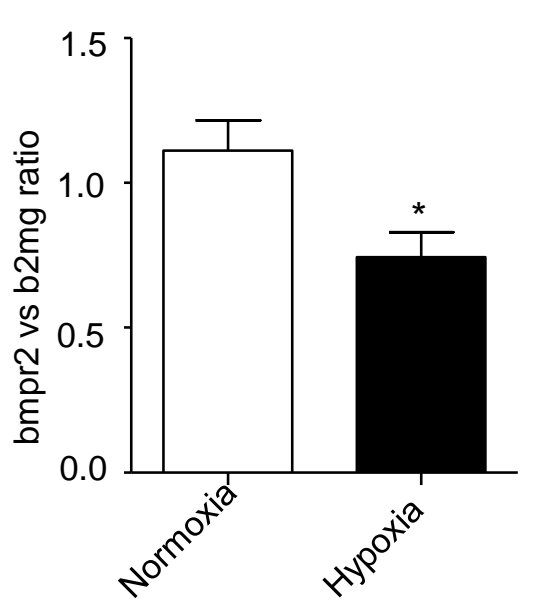

B

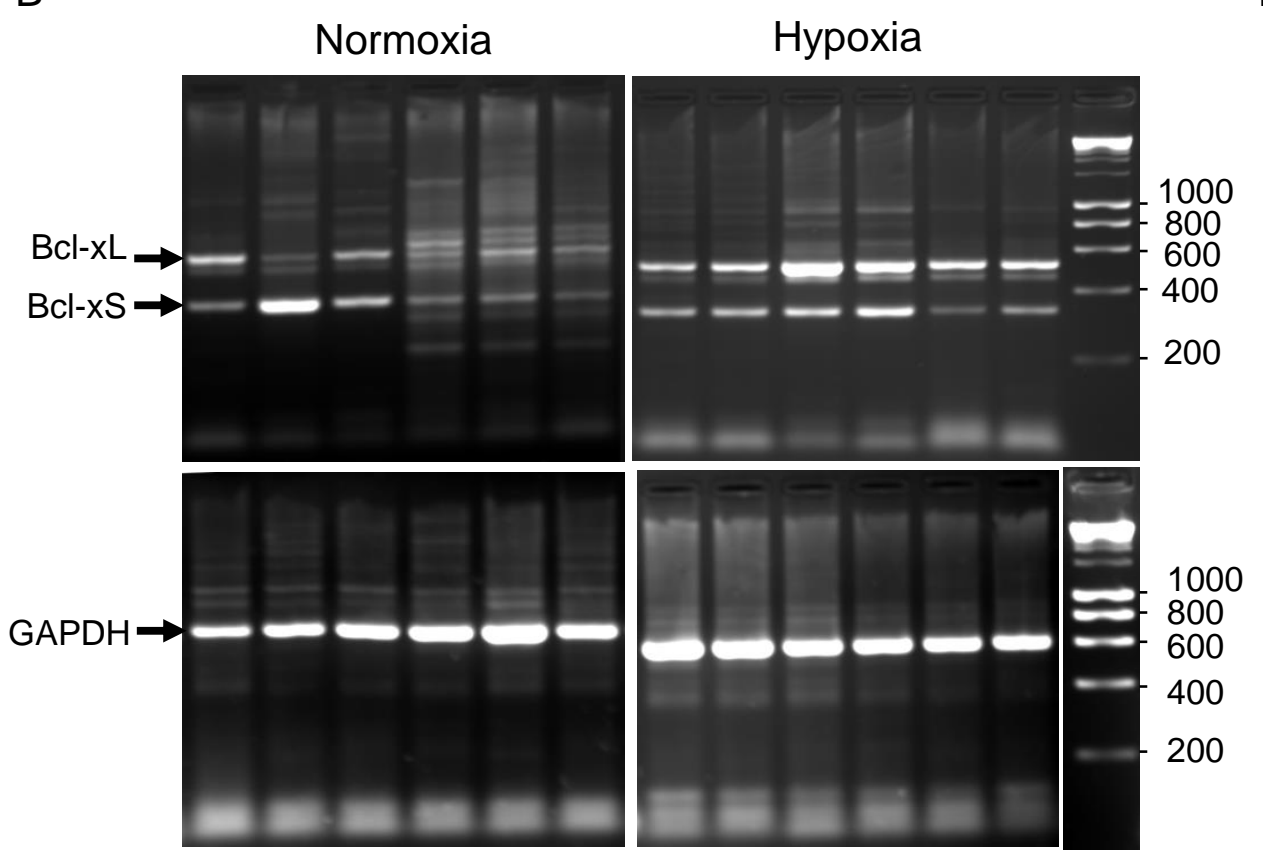

C

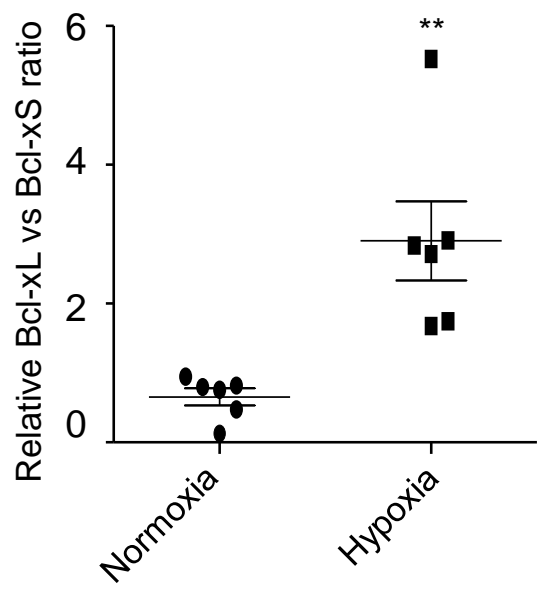

D

Figure 2

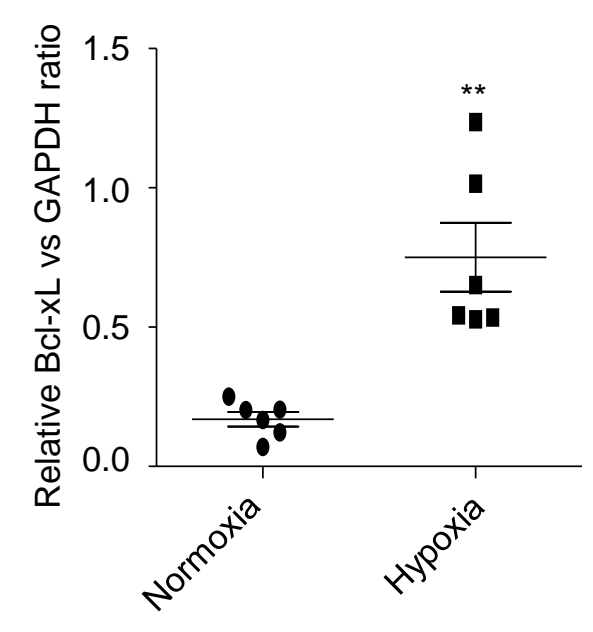




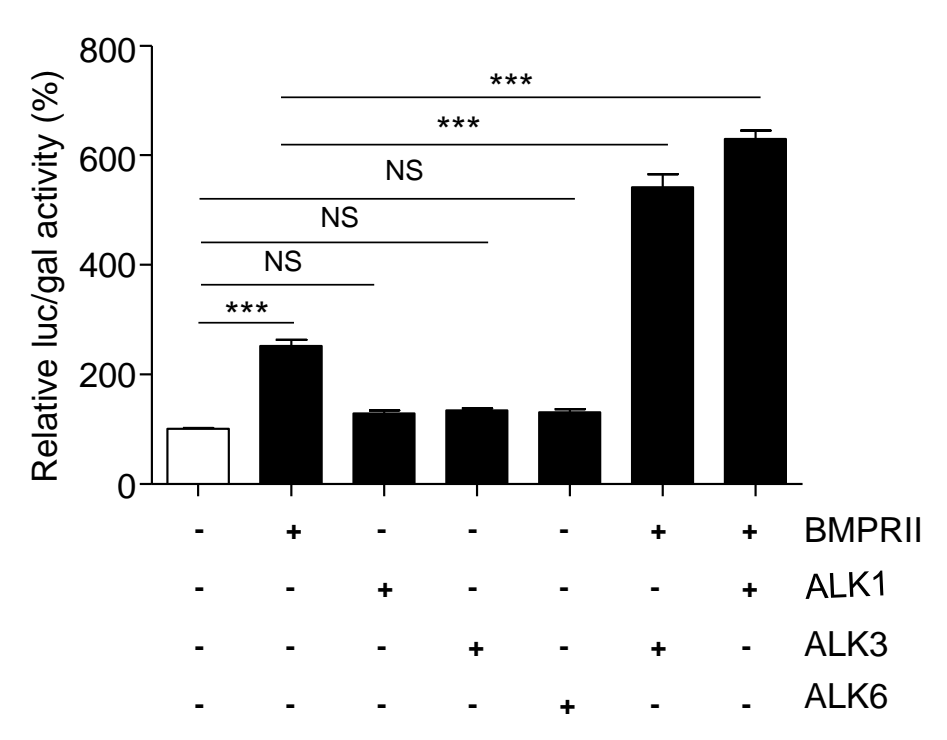

B

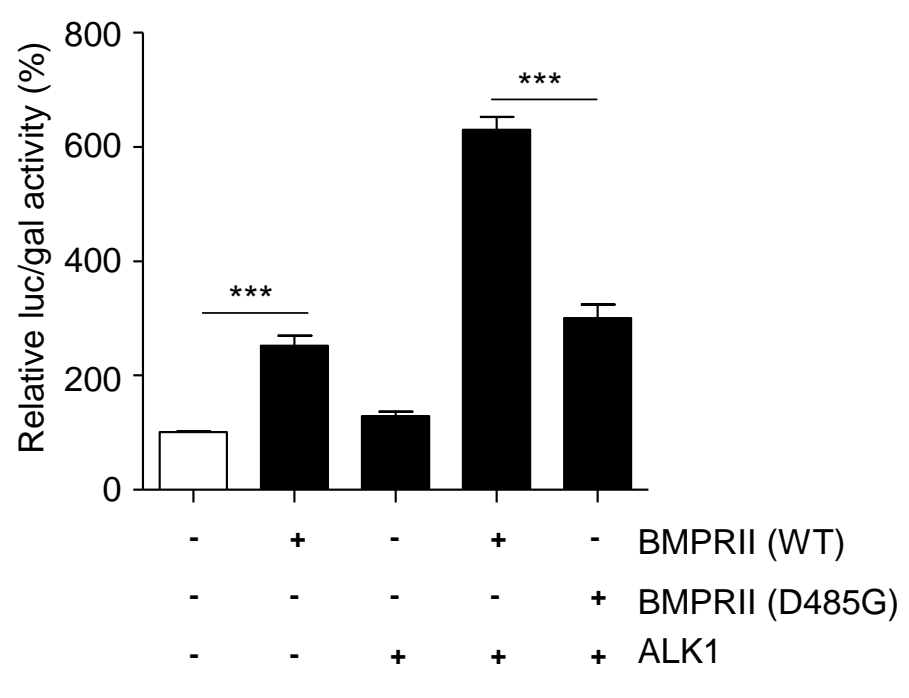

D

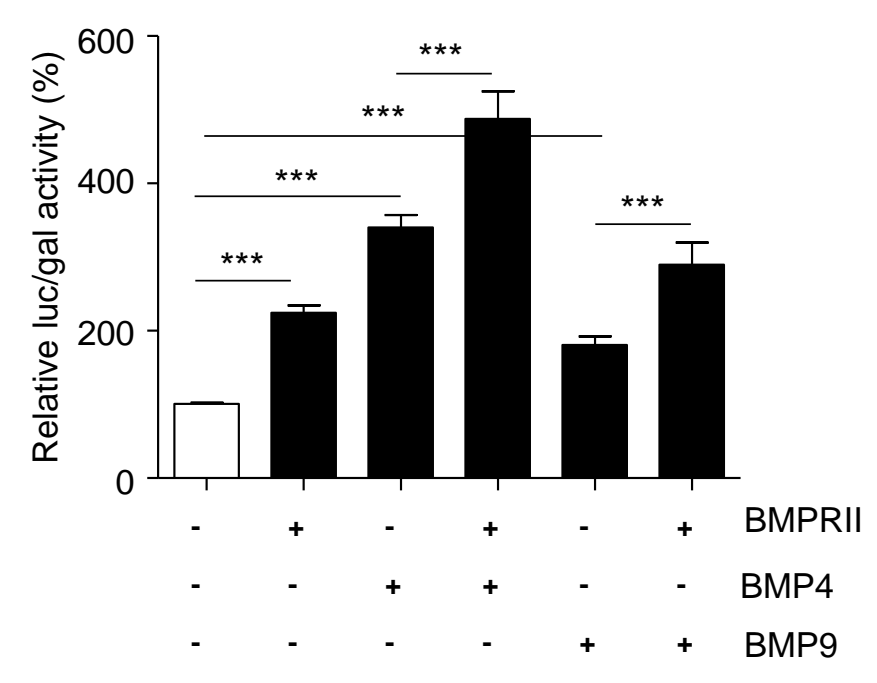

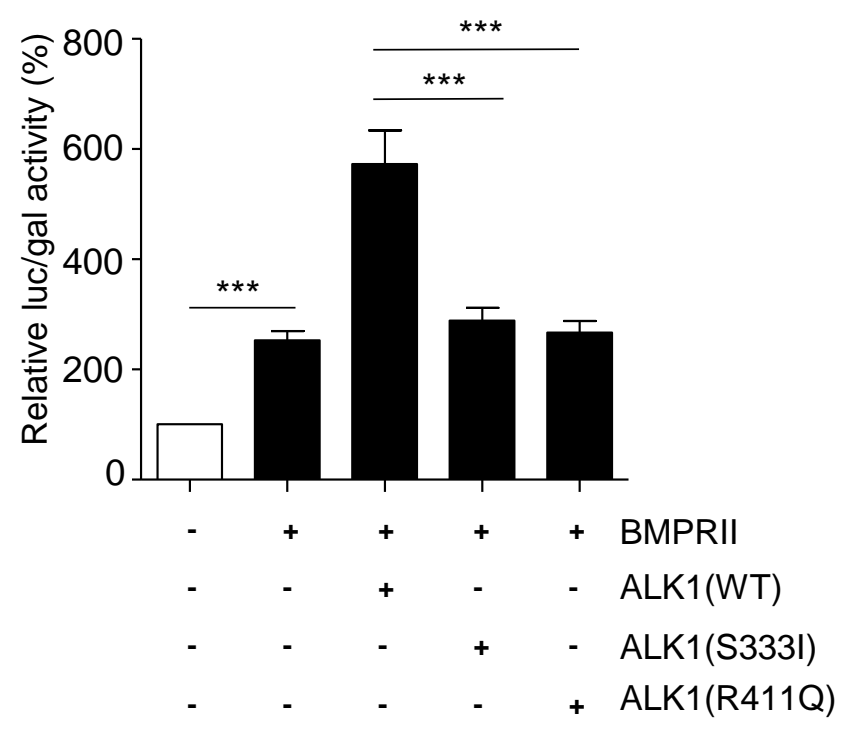




\section{A}

\begin{tabular}{|l|l|l|l|}
\hline SV40 & $\beta$-gal & D/A unit & Luciferase \\
\hline
\end{tabular}

No interaction

$\beta$-gal

BMPRII-ALK1

interactions

$\beta$-gal

B
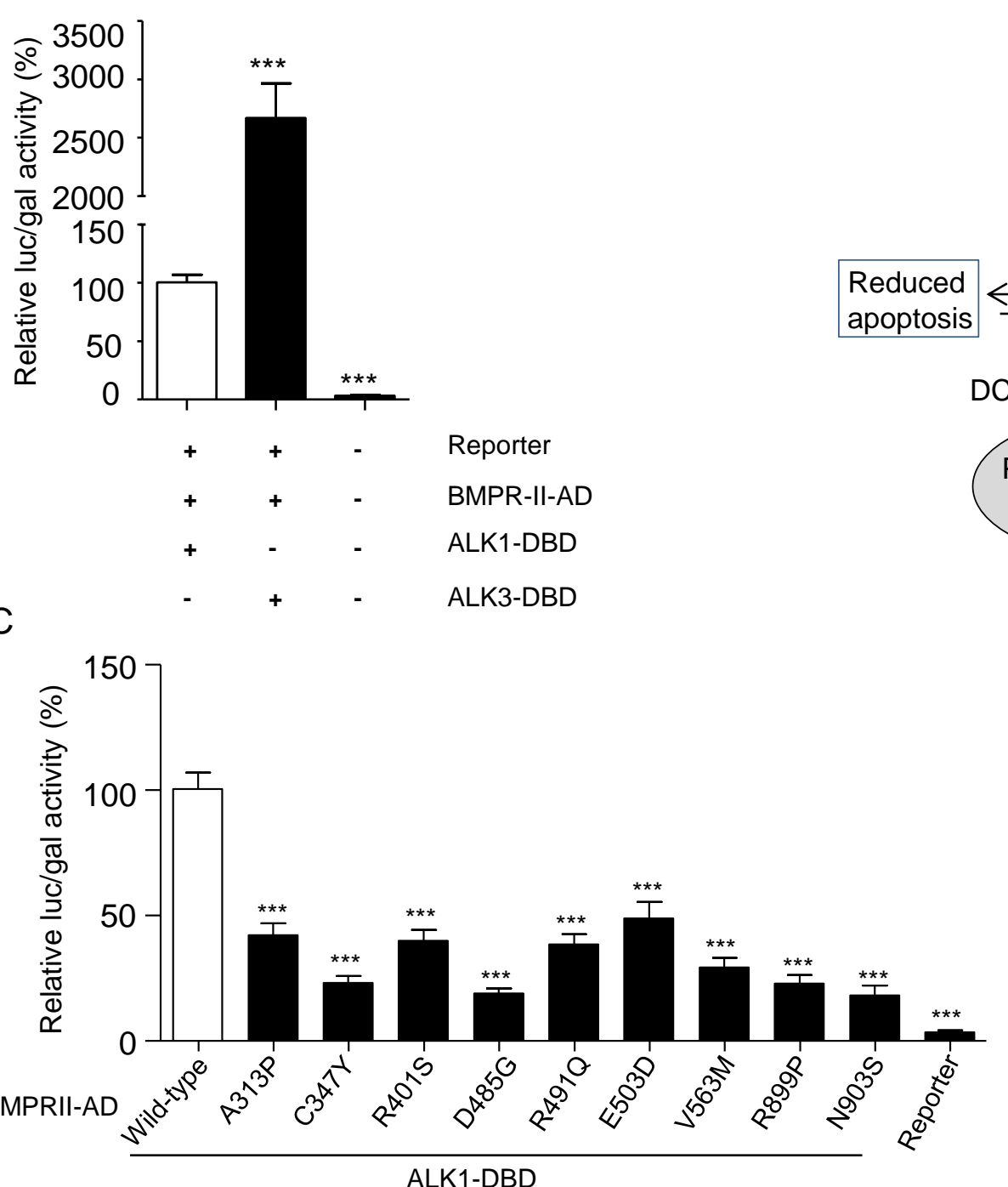

D

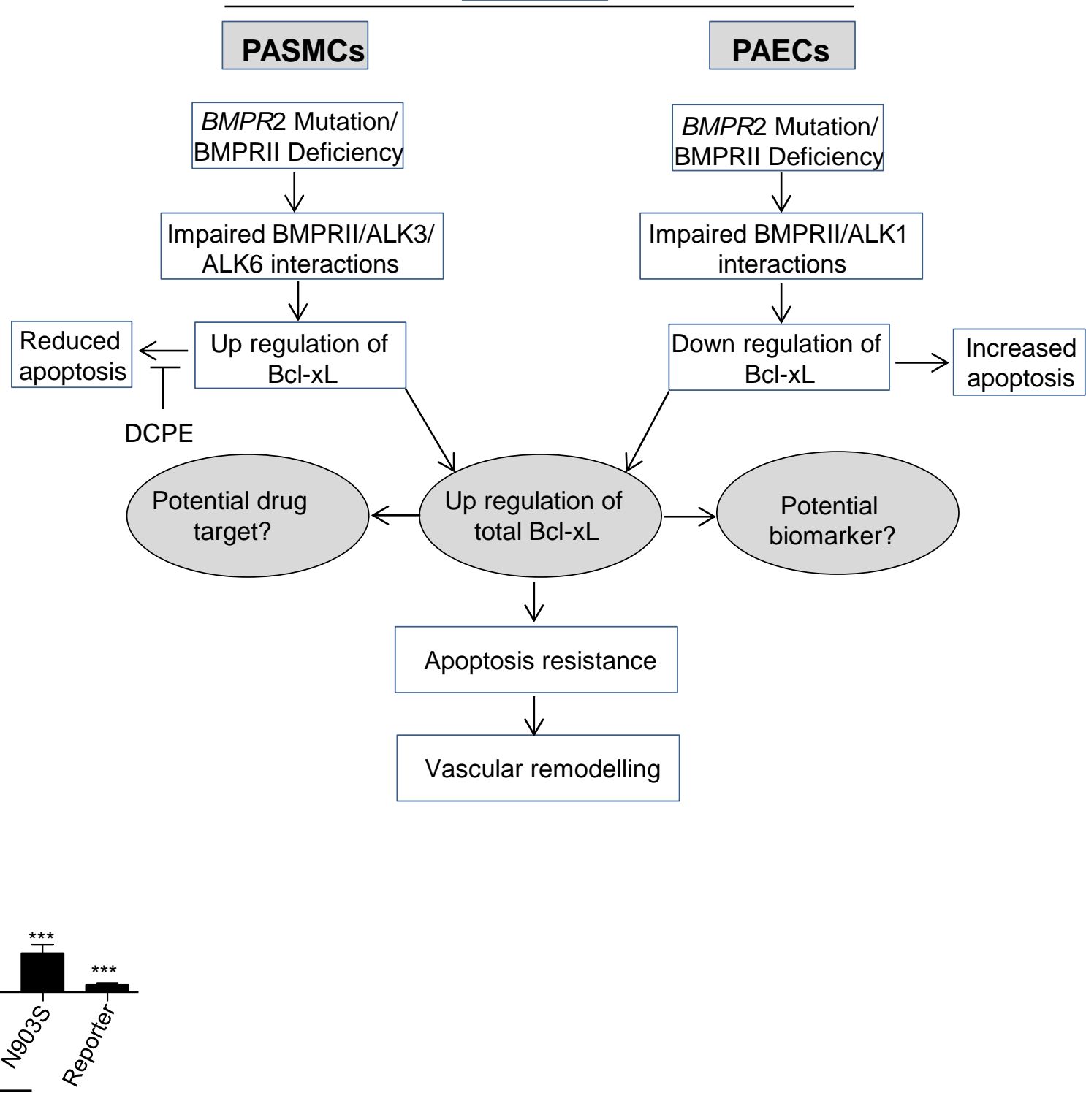




\section{Supplementary Figure 1}

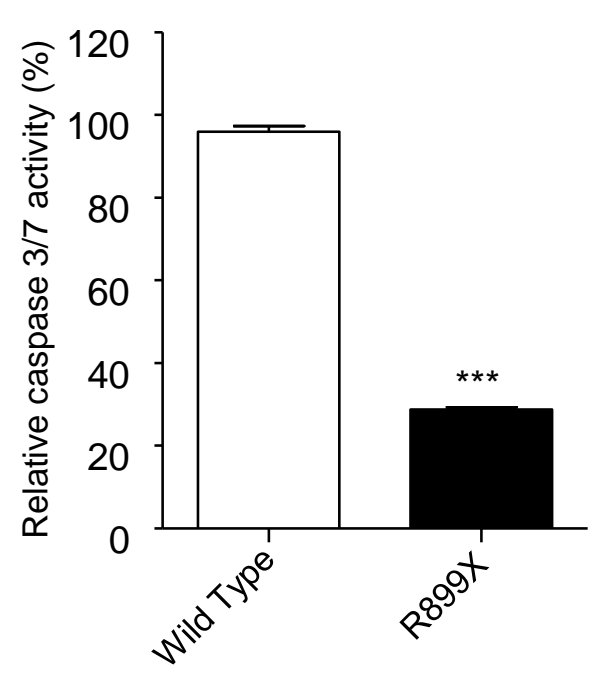




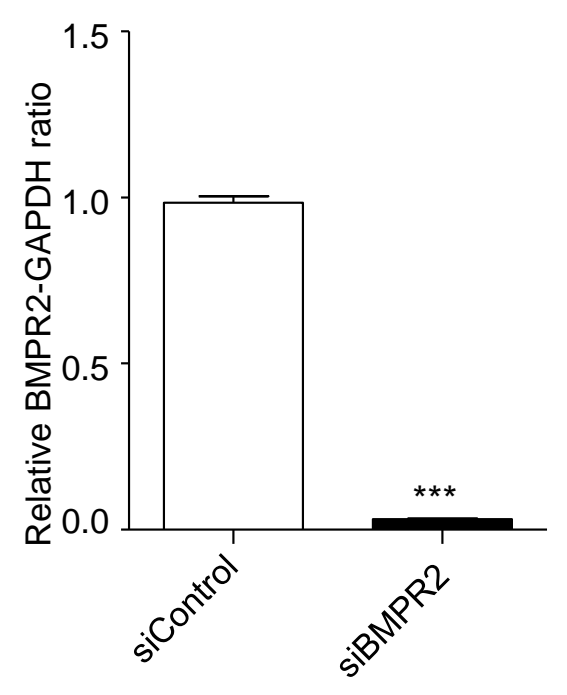

B

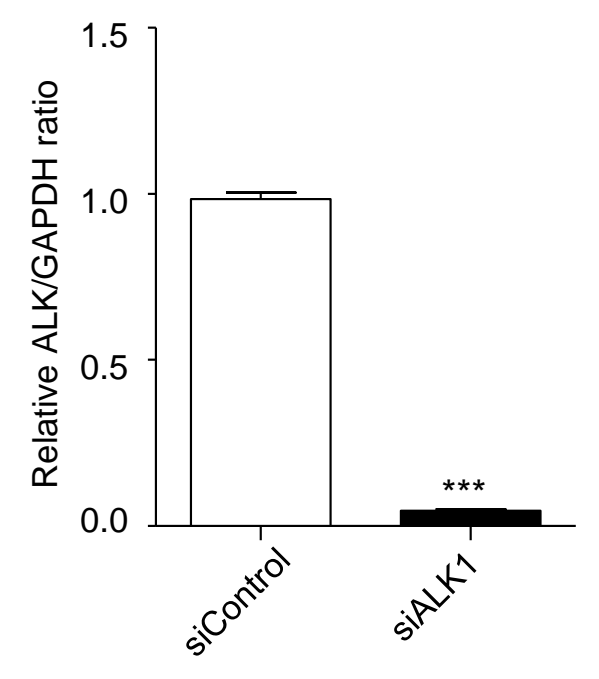



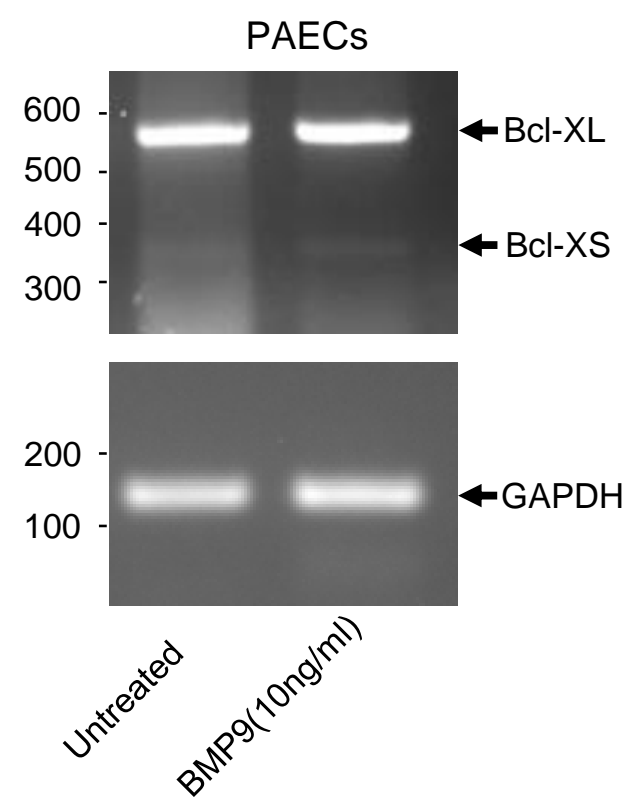

B

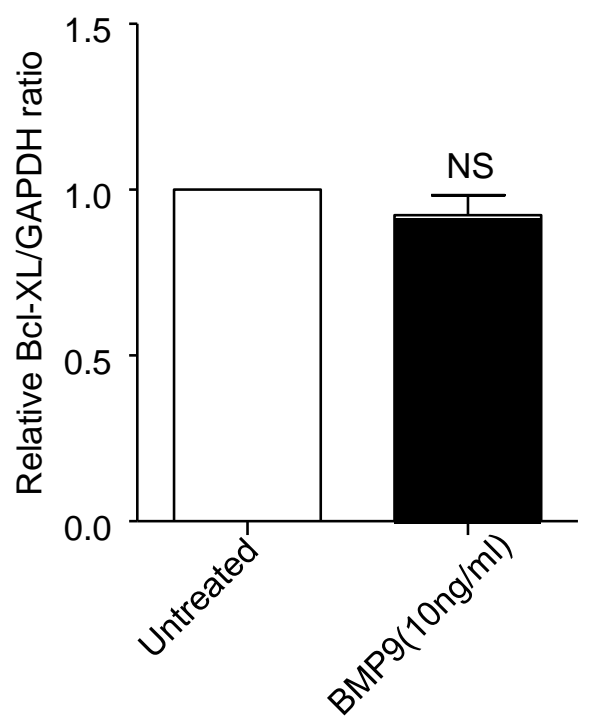



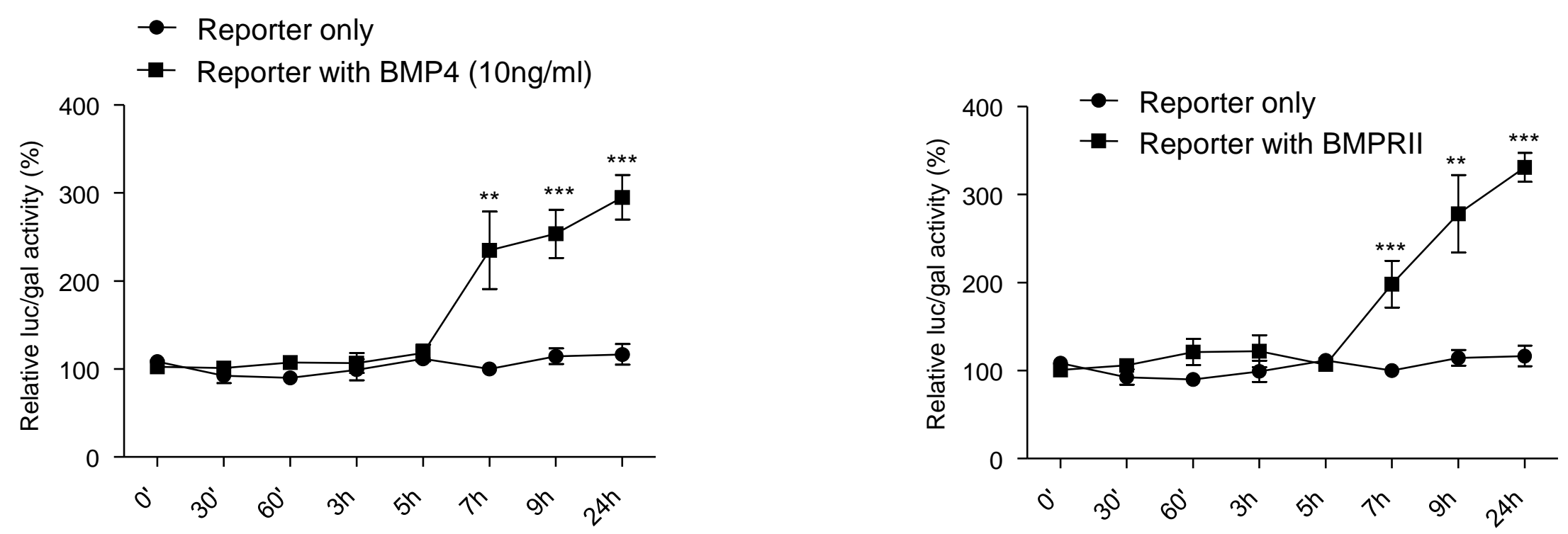


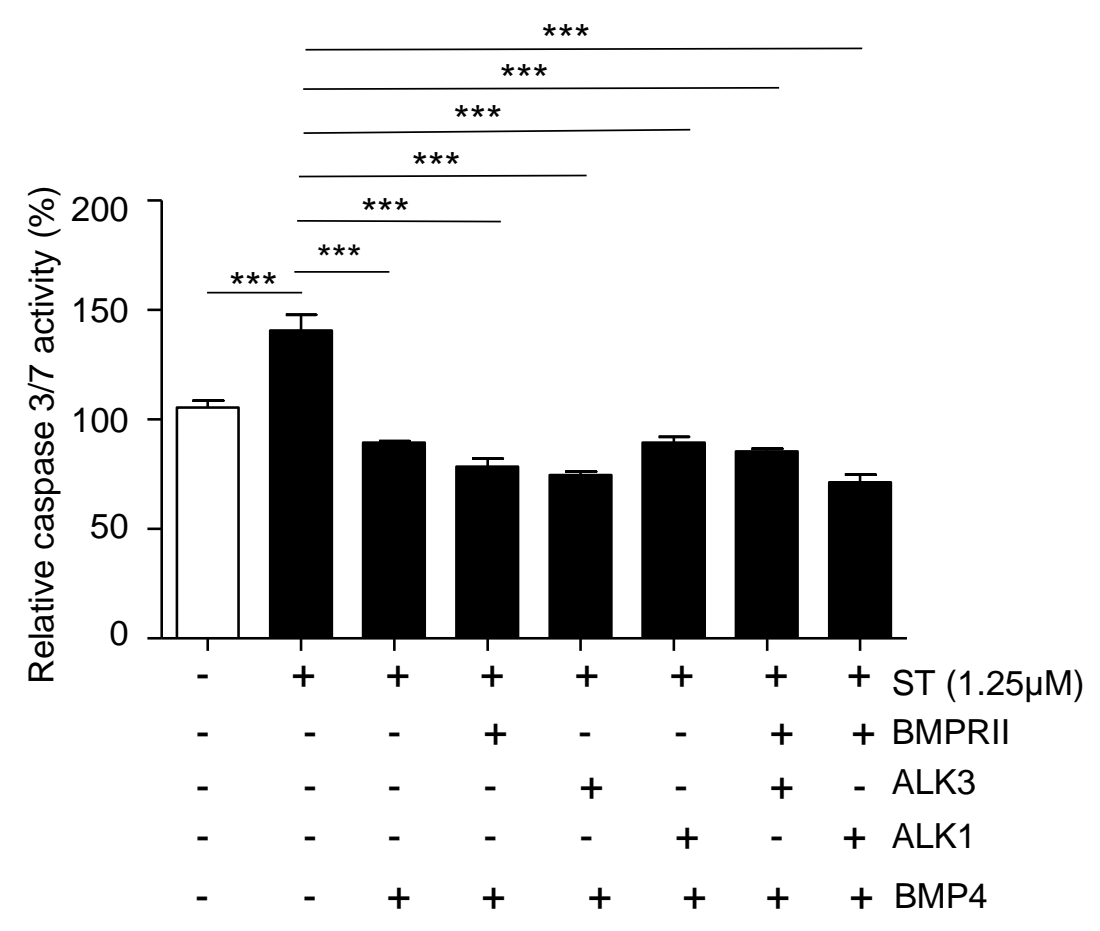




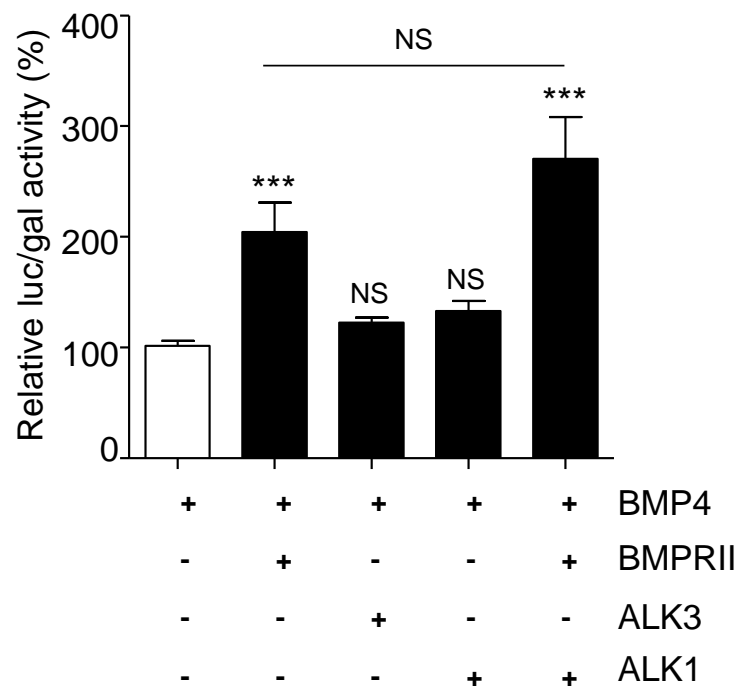

B

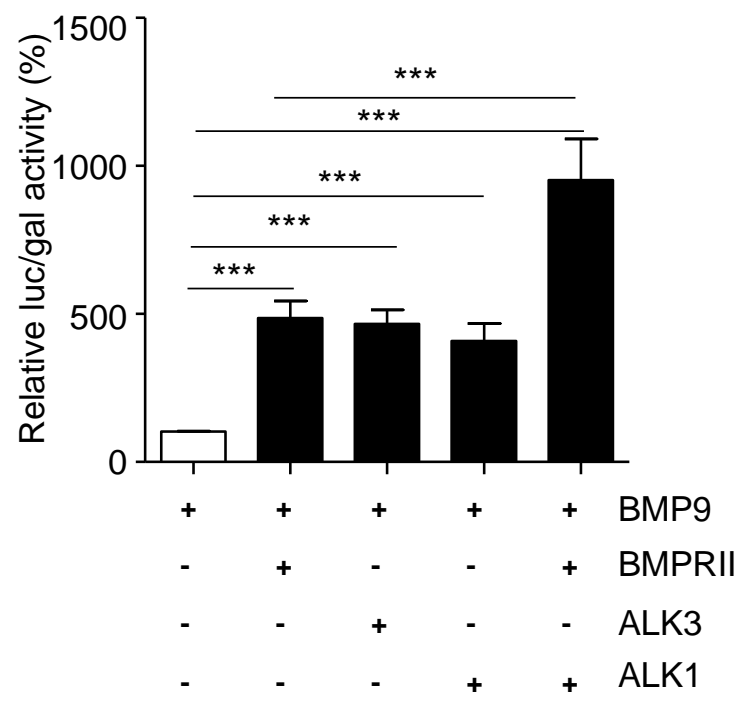


A

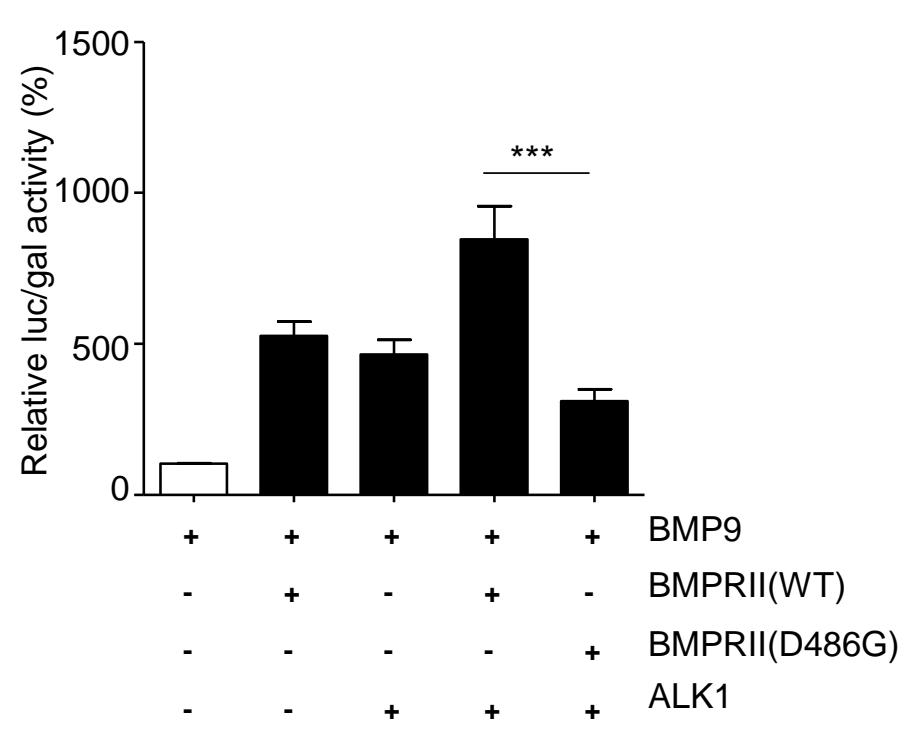

B

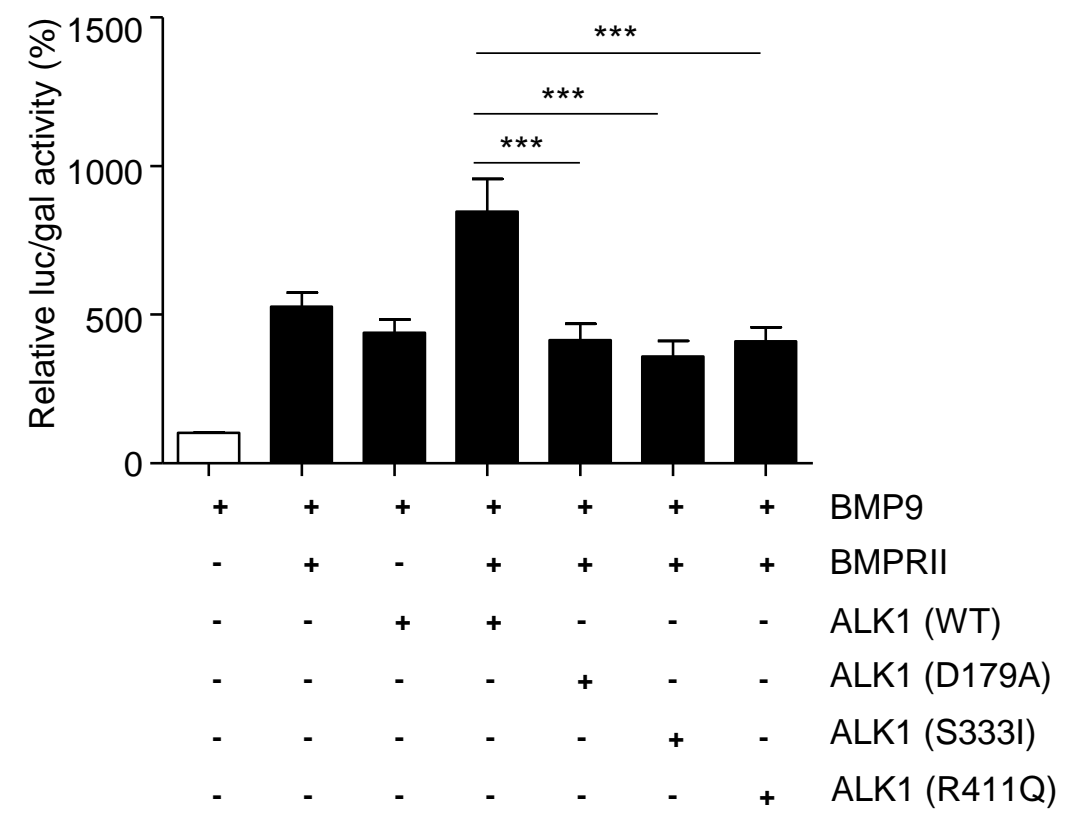




\section{SUPPLEMENTARY INFORMATION}

\section{Figure legends}

\section{Supplementary Figure 1}

Effect of BMPR2 mutation on apoptosis in mouse PASMCs as determined by caspase 3/7 activities. PASMCs were derived from wild-type and mutant mice harbouring the pathogenic BMPR2 mutation (p.R899X). The activity level of caspases 3 and 7 was attenuated in mutant (p.R899X) cells compared with wild-type $(n=8) .{ }^{* * *} P<0.001$ compared with wild-type.

\section{Supplementary Figure 2}

Effects of siRNA knock-down on BMPR2 and ALK1 transcripts as determined by qPCR. Reduced levels of BMPR2 and $A L K 1$ transcripts were observed in cells transfected with siRNAs at a concentration of $30 \mathrm{nM}$ compared with that of controls (siControl). Quantification of the relative BMPR2 vs GAPDH (A) and $A L K 1$ vs GAPDH (B) ratios of qPCR $(\mathrm{n}=4)$. ${ }^{* * *} \mathrm{P}<0.001$ compared with non-targeted siRNA.

\section{Supplementary Figure 3}

PAECs treated with BMP9 ligand elicited no discernible effect on the preferential expression of Bcl-x. (A) RT-PCR analysis of Bcl-xS and Bcl-xL transcripts in PAECs stimulated with BMP9 ligand $(10 \mathrm{ng} / \mathrm{ml})$. (B) Quantification of the RT-PCR images $(n=4)$. The RT-PCR of GAPDH was used as an internal standard. NS-non significant.

\section{Supplementary Figure 4}

The BMP signalling promoting activity of BMP4 ligand and BMPRII receptor. (A) Diagram depicting the BMP signalling cascade as determined by the BMP responsive 3GC2-Lux reporter assay. HEK293T cells transfected with the 3GC2-Lux reporter were stimulated with the ligand $(10 \mathrm{ng} / \mathrm{ml})$ at various time points $(30 \mathrm{mins}, 1 \mathrm{~h}$, 3hrs, $5 \mathrm{hrs}, 7 \mathrm{hrs}, 9 \mathrm{rs}$ and $24 \mathrm{hrs})$ without (B) and with BMPRII (C) overexpression and their luciferase and $\beta$-galactosidase activities were determined $(n=6)$. The luc-gal activities of cells at 0 h time point were set as 100. ${ }^{* *} \mathrm{P}<0.01,{ }^{* * *} \mathrm{P}<0.001$ compared with control treated for 0 hour.

\section{Supplementary Figure 5}

ALK1 and BMPRII significantly inhibit staurosporine (ST)-induced caspase activity. HEK293T cells overexpressed with ALK1, ALK3 and BMPR-II receptors were treated with apoptosis-inducing agent staurosporine $(1.25 \mu \mathrm{M})$ and stimulated with BMP4 ligand $(10 \mathrm{ng} / \mathrm{ml})$ for 16 hours $(\mathrm{n}=4)$. The rate of apoptosis was determined using the Caspase-Glo ${ }^{\circledR}$ 3/7 Assay (Promega). ${ }^{* \star *} \mathrm{P}<0.001$ compared with untreated control, NS-non significant.

\section{Supplementary Figure 6}

Effects of ALK1 on BMP4 and BMP9-mediated signalling as determined by the 3GC2-LuX reporter assay. HEK293T cells co-expressing 3GC2-Lux, BMPRII, ALK3 and ALK1 and stimulated with either BMP4 (A) or BMP9 (B) at a concentration of $10 \mathrm{ng} / \mathrm{ml}(\mathrm{n}=4)$. ALK1BMPRII-mediated reporter activation was significantly increased compared with cells stimulated with either of BMP4 or BMP9 ligands. The luc-gal activity of ligand stimulated cells was set as $100 .{ }^{* *} \mathrm{P}<0.001$ compared with ligand stimulated control, NS-non significant.

\section{Supplementary Figure 7}

Effects of BMPR2 and ALK1 mutation on BMP9-mediated signalling as determined by the reporter assay. Mutation in either BMPRII or ALK1 receptor significantly reduced BMP9- 
mediated reporter activation. (A) Mutation in the kinase domain of BMPRII receptor (p.D485G) significantly reduced BMP9-ALK1-mediated reporter activation. HEK293T cells transfected in combination with either wild-type or mutant BMPRII receptor with and without ALK1 $(n=8)$. (B) As (A), cells transfected in combination with wild-type and mutant ALK1 receptor with and without BMPRII $(n=6)$. The luc-gal activity of BMP9 ligand stimulated cells was set as 100. ${ }^{* \star} \mathrm{P}<0.001$ compared with ligand stimulated control. 